\title{
Dendrimer-based signal amplification of click-labelled DNA in situ
}

\author{
Nada Raddaoui\#, Samuele Stazzoni”, Leonhard Möckl, Bastien Viverge, Florian Geiger, Hanna Engelke, \\ Christoph Bräuchle and Thomas Carell*
}

Center for Integrated Protein Science (CiPSM) at the Department of Chemistry, LMU München, Butenandtstr. 5-13, 81377 München.

\# contributed equally, ${ }^{*}$ correspondence to Thomas.Carell@Imu.de

Published online in ChemBioChem 22.06.2017, DOI: 10.1002/cbic.201700209, print: Vol.18(17):1716 - 1720

\begin{abstract}
The in vivo incorporation of alkyne modified bases into the genome of cells is today the basis for efficient detection of cell proliferation. Cells are grown in the presence of ethinyl-dU (EdU), fixed and permeabilized. The incorporated alkynes are then efficiently detected using azidecontaining fluorophores and the $\mathrm{Cu}(\mathrm{I})$ catalyzed alkyne-azide click reaction. In a world where constant improvement of the sensitivity of a given method is driving diagnostic advancement, we developed azide and alkyne modified dendrimers that allow to establish sandwich-type detection assays that show significantly improved signal intensities and signal to noise ratios far beyond of what is currently possible.
\end{abstract}

The proliferation rate of cells is a key parameter that requires in many contexts precise determination. ${ }^{[1]}$ Cell proliferation assays help for example routinely to evaluate the toxicity of compounds in the framework of the development of new pharmaceuticals. ${ }^{[2]}$ Also in cancer diagnostics, it is required to measure the proliferation of cells with high precision. ${ }^{[3]}$ Particularly in this field highest sensitivity is desired in order to detect at best even single cancer cells in a patient sample. Today the most precise way to measure cell proliferation is to culture the cells in the presence of C5-ethinyl-dU (EdU), which is incorporated into the genome of proliferating cells as a typical anti-metabolite. ${ }^{[4]}$ The amount of incorporated EdU is subsequently measured by reacting the alkynes within the DNA with azidomodified fluorescent dyes using the $\mathrm{Cu}(\mathrm{I})$ catalysed alkyne-azide click reaction ${ }^{[5]}$ and detected using fluorescent microscopy. ${ }^{[6]}$ This reactions proceed on DNA with extreme efficiency likely because the $\mathrm{Cu}(\mathrm{I})$ is loosely pre-coordinated to the electron rich centers at the nucleobases. ${ }^{[6]}$ This technology is used in established commercially available kits (EdU-Click kit from baseclick, Click-iT from Thermo Fisher). However in all available methods, the sensitivity is limited by the number of alkynes, which are incorporated during the culturing phase of the experiment in the presence of EdU (one alkyne). This creates the problem that slowly proliferating, but still cancerogenous cells often escape detection. ${ }^{[7]}$ We report here a sandwich-type approach with alkyne and azide containing dendrimers 1 and 2 (Scheme 1) that allows significant chemical signal amplification. The method was shown to provide unprecedented detection sensitivities of proliferating cells. The synthesis of the needed amplifying tetraazide/alkyne molecules $\mathbf{1}$ and $\mathbf{2}$ is depicted in Scheme 1 (and S1, S2). In both cases, the principle design idea was to stay as close as possible to polyethyleneglycol based structures because of the needed high solubility in water. Starting point towards $\mathbf{1}$ is the ethylene glycol derivative $\mathbf{3}$, which we converted first into the azide $\mathbf{4}$. The hydroxyl group was subsequently tosylated to 5 to enable the fourfold substitution reaction with ethylenediamine to give the desired tetraazide compound 1.
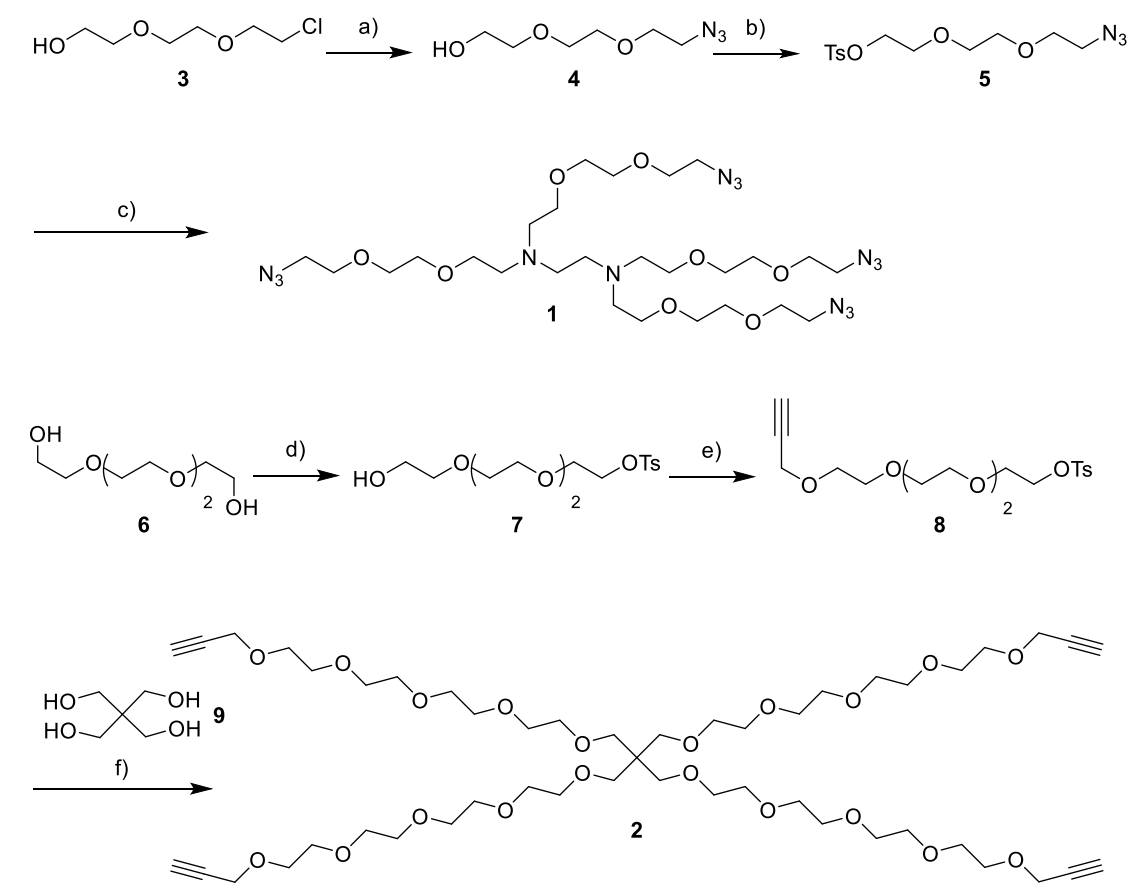

Scheme 1. Synthesis of the ethylene glycol based tetraazide 1 and of the tetraalkyne 2 needed for the study. Reagents and conditions: a) $\mathrm{NaN}$, DMF, $90^{\circ} \mathrm{C}$, o/n, $96 \%$. b) $\mathrm{TsCl}, \mathrm{NEt}_{3}, \mathrm{CH}_{2} \mathrm{Cl}_{2}$, o/n, 90\%. c) ethylenediamine, 5, $\mathrm{KOH}, \mathrm{LiBr}, \mathrm{DMF}, 60^{\circ} \mathrm{C}, \mathrm{o} / \mathrm{n}, 63 \%$. d) $\mathrm{TsCl}, \mathrm{NEt} 3, \mathrm{THF}, \mathrm{rt}, \mathrm{o} / \mathrm{n}, 92 \%$. e) propargyl bromide, $\mathrm{NaH}, \mathrm{THF}$, $0^{\circ} \mathrm{C}$ to rt, $82 \%$ f) $8, \mathrm{~K}_{2} \mathrm{CO}_{3}$, acetone, $80^{\circ} \mathrm{C}, \mathrm{o} / \mathrm{n}, 31 \%$. 
The synthesis of the tetraalkyne $\mathbf{2}$ started with the ethyleneglycol derivative $\mathbf{6}$, which was monotosylated in excellent yield to provide $\mathbf{7}$. Reaction with propargyl bromide furnished compound $\mathbf{8}$, which was used for a fourfold substitution reaction with pentaerythritol $\mathbf{9}$ to give the dendrimer $\mathbf{2}$. Both compound $\mathbf{1}$ and $\mathbf{2}$ were subsequently purified by flash column chromatography.

In a first approach to amplify the cell proliferation signal, we used the polyethyleneglycol based tetraazide molecule $\mathbf{1}$ as shown in Figure $1 \mathrm{~A}$ and S3. For the experiments, we grew HeLa cells in $\mu$-slides in the presence of $10 \mu \mathrm{M}$ EdU for $2 \mathrm{~h}$. The medium was removed and $3.7 \%$ formaldehyde in phosphate buffered saline supplemented with $0,02 \%$ Tween (1x PBS-T) buffer was added to fix the cells. After two time washing with $1 \times$ PBS-T, the cells were permeabilized with $0.5 \%$ Triton X-100 in $1 \times$ PBS-T for 20 min at room temperature (RT). We then added the click-cocktails successively. In one experiment, we just added the Tamra-azide 10 (20 $\mu \mathrm{M})$ as a positive control. In the other experiment, we performed a first reaction with the dendrimer $1(20 \mu \mathrm{M})$ for $1 \mathrm{~h}$ followed by a second click reaction with the Tamra-alkyne $11(5 \mu \mathrm{M})$ for 30 minutes (For more detailed characterization of the reaction products, determined with a symplified model using synthetic oligonucleotides see SI). In both experiments, we washed the fixed cells twice with $3 \%$ BSA in PBS buffer. In the dendrimer amplified experiment with the Tamra-alkyne $\mathbf{1 1}$ we noted an unusually high background even after these intensive washing steps. Screening for appropriate washing conditions showed that best results were obtained when we washed with a solution of guanidinium isocyanate (Fig. S4). We then determined the Tamra fluorescence using a fluorescence microscope. The data are depicted in Fig. 1B. Clearly visible is that the prior click with the dendrimer-azide 1 furnished a six-fold increase of the fluorescence signal. This was particularly visible in the fluorescence microscopic evaluation of the click-modified cells (Fig. 1C).
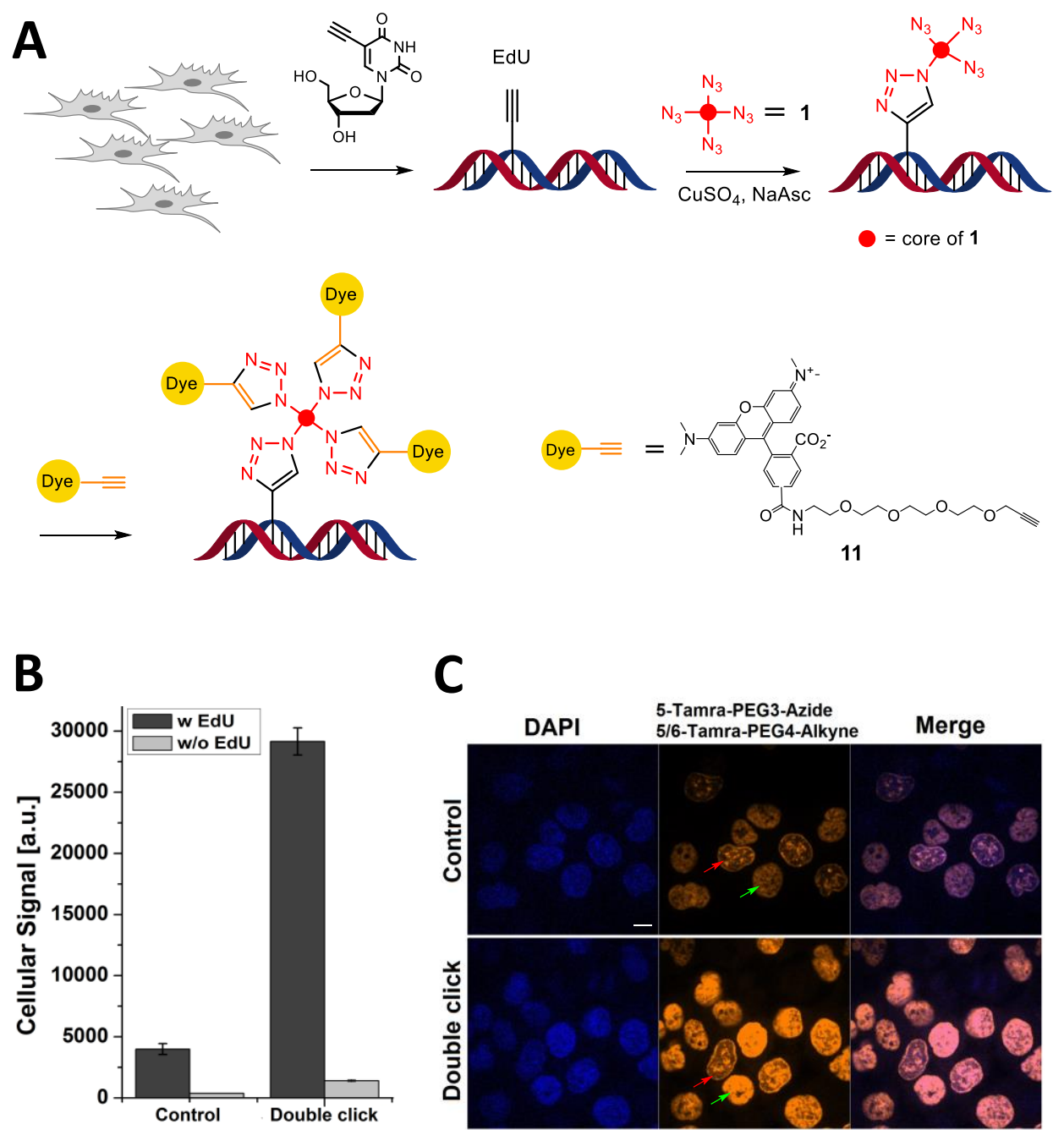

Figure 1. A) Depiction of the single dendrimer (double click) amplified cell proliferation assay. Cells were grown in the presence of 5-ethinyl-dU. The cells were fixed and the present alkynes reacted with a tetraazide-dendrimer 1 in the presence of $\mathrm{Cu}(\mathrm{I})$ (double click). The multiple azide containing DNA is then detected in situ with an alkyne-modified dye $\mathbf{1 1}$ using again the $\mathrm{Cu}(\mathrm{I})$ catalyzed click reaction. B) The control experiment is performed using the dendrimer-free standard proliferation assay with 10. Double click shows data after dendrimer amplification. C) Fluorescence microscopy pictures of cells detected with the standard assay as control (top) and after dendrimer amplification (bottom). Red arrays show cells in the early S-phase with partial EdU incorporation. Green arrows show cells in late S-phase, where the DNA synthesis is almost finished and EdU is incorporated into the whole genome. Scale bars, $20 \mu \mathrm{m}$.

We noted that after extensive washing with guanidinium isocyanate, the background was reduced but steadily higher than in the nondendrimer experiments. We speculated that this background problem may be caused by the dye-alkyne $\mathbf{1 1}$ possibly because alkynes are known to react to some extent with nucleophiles. Thiol-containing nucleophiles are abundantly present in cells. Control experiments performed without the addition of the tetraazide 1 confirmed this hypothesis and showed a still high background signal even without using our dendrimers (Fig. S4). 
In order to solve the background problem and to further increase the sensitivity (signal to noise ratio) of detection, we experimented next with a double-dendrimer approach (Fig. 2) where we first reacted the fixed DNA with the tetraazide 1, followed by an additional click reaction with the tetraalkyne-dendrimer 2 . This was then followed by a final click reaction with the Tamra-azide 10 (Fig. S5). In this way, we planned to circumvent the use of the problematic dye-alkynes.
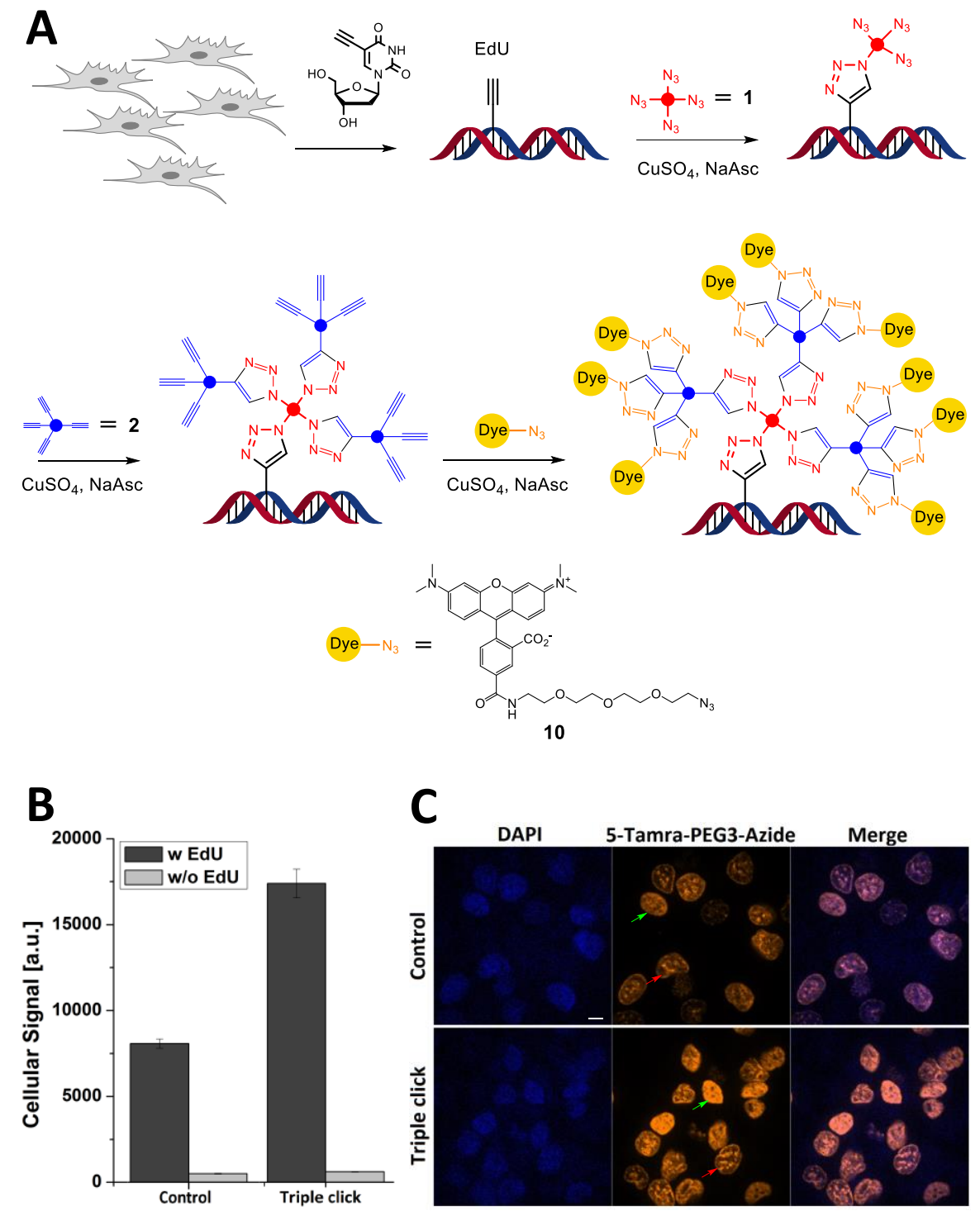

Figure 2. A) Depiction of the double dendrimer (triple click) amplified cell proliferation assay. Cells were grown in the presence of 5-ethinyl-dU. After fixation and permeabilization, the present alkynes are first reacted with the tetraazide-dendrimer 1 in the presence $\mathrm{Cu}(\mathrm{I})$. The multiple azide containing DNA is then reacted with the tetraalkyne 2. The so double modified DNA (triple click) is finally detected with an azide-modified dye 10 using again the Cu(I) catalyzed click reaction. B) The control experiment is performed using the dendrimer-free standard proliferation assay. Triple click shows data after double dendrimer amplification. C) Fluorescence microscopy pictures of cells detected with the standard EdU assay as control (top) and after double dendrimer amplification with triple click (bottom). Red arrows show cells in the early S-phase. Green arrows show cells in late S-phase. Scale bars, $20 \mu \mathrm{m}$.

For this experiment, we again cultured HeLa cells in $\mu$-slides in the presence of $10 \mu \mathrm{M}$ EdU for $2 \mathrm{~h}$. The medium was removed and $3.7 \%$ formaldehyde in $1 \times$ PBS-T was again added to fix the cells. We washed the cells two times with $1 \times$ PBS-T and permeabilized the cells with $0.5 \%$ Triton in $1 \times$ PBS-T for 20 min at RT. We then added the click-cocktails successively: First we added $\mathrm{Cu}(\mathrm{I})$ and tetraazide 1. We washed the cells twice with a $0.2 \mathrm{M}$ acetate buffer $\mathrm{pH} 4.7$ followed by two washing steps with $1 \times$ PBS-T and performed subsequently the second click reaction with tetraalkyne 2 and $\mathrm{Cu}(\mathrm{I})$ for $1 \mathrm{~h}$. The cells were again washed twice with $1 \mathrm{x}$ PBS-T. Finally we added $\mathrm{Cu}(\mathrm{I})$ and the Tamra-azide $\mathbf{1 0}$ to the cells and allowed the final click cocktail to penetrate the cells for 30 minutes. After again two time washing with guanidinium isocyanate we studied the cells by fluorescence microscopy. This time the experiment was a full success. We detected a strongly reduced background, not higher than in the control experiment with just EdU (Fig. 2B,C). The obtained fluorescence signal was highly improved by a factor of 2.5. Most importantly, the direct inspection of the cells by fluorescence microscopy shows a strongly improved signal to noise ratio (Fig. 2C, S5).

Next, the new single and double dendrimer based methods were applied for high throughput screening (HTS). This method is the most widely used tool not only for the development of new pharmaceuticals compounds but also needed for the measurement of the response of cells to different nutrients, mitogens, cytokines, growth factors and toxic agents ${ }^{[8]}$. With the signal amplification provided by our dendrimers, we were able to detect a strong, specific signal even when only a very small number of cells like just 100 cells were present 
per well (Fig. 3). This is a significant improvement over contemporary methods that need 500 to 1000 cells per well, which allows now the reliable detection of small number of proliferating cells that otherwise escape staining and detection. What we noted, however, is a reduction of the signal intensity in the double-dendrimer approach, which is likely due to self-quenching of the then densly packed fluorophores. To solve this, optimization of the dendrimers is now required.

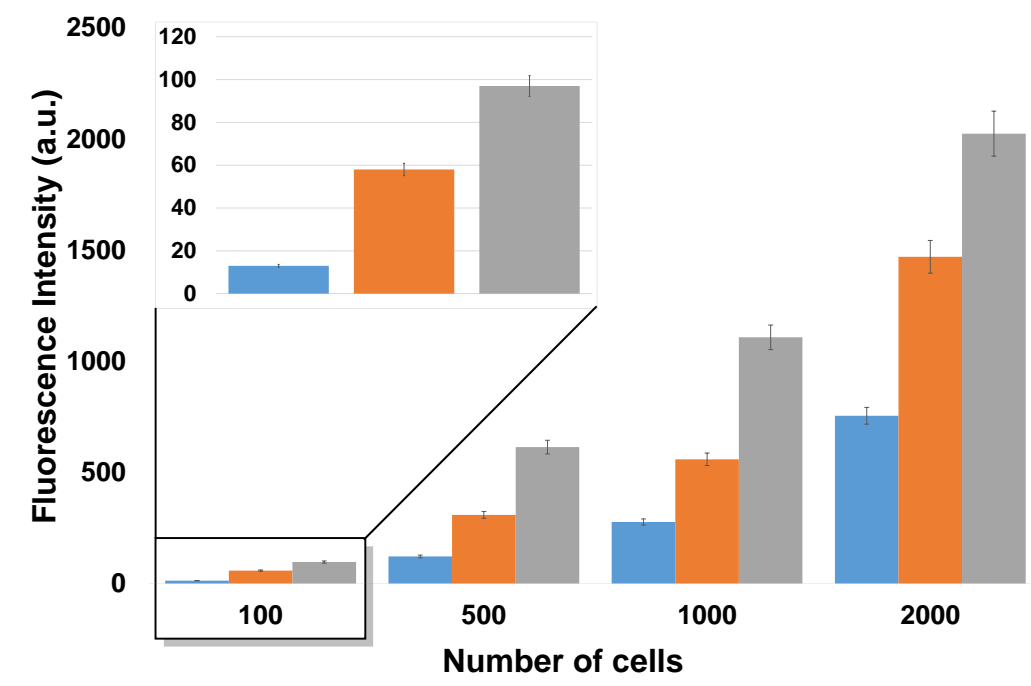

Figure 3: Application of the single and double dendrimer amplified assay in high throughput screening. Cells were grown on microplate with different densities (100 500,1000 and 2000 cells/well) and incubated for $2 \mathrm{~h}$ with 5 -ethinyl-dU at $37^{\circ} \mathrm{C}$. Negative control cells were grown without EdU labeling. The cells were fixed and permeablized and the present alkynes reacted with a tetraazide dendrimer $\mathbf{1}$ and Tamra-alkyne (double click, gray bars) or with tetraazide $\mathbf{1}$, tetraalkyne $\mathbf{2}$ and Tamra-azide (triple click, orange bars) in the presence of $\mathrm{Cu}(\mathrm{I})$ in situ. Positive control cells were reacted with Tamra-azide in presence of $\mathrm{Cu}(\mathrm{I})$ (control, blue bars). The cellular signal of duplicate samples was measured with a Tecan microplate reader. After subtraction of the background fluorescence, it was possible to detect a stronger signal even with only 100 cells. Blue: Standard click protocol. Grey: Single dendrimer approach with dendrimer 1. Orange: Double dendrimer approach with the dendrimers 1 and 2.

In summary, click-based detection of cell proliferation is today state-of-art technology. We show here that by using dendrimer-type tetraazide (1) and dendrimer-type tetraalkyne (2) compounds sandwich type detection assays can be established that yield strongly improved signal intensities with low background giving higher signal to noise ratios for imaging and high throughput content assays. We expect that the so improved cell proliferation assay will be able to detect either slowly or even single proliferating cancer cells with unprecedented sensitivity.

\section{Acknowledgements}

We thank the Deutsche Forschungsgemeinschaft for financial support via SFB1032 (TP-A5), SFB749 (TP-A4), SPP1784, CA275 and the Excellence Cluster CiPS ${ }^{\mathrm{M}}$. Further support from the European Union via the Marie Curie International Training and Mobility Network "Clickgene" (grant No. 642023) is acknowledged.

Keywords: click chemistry $\bullet$ cell proliferation $\bullet$ dendrimer $\bullet$ fluorescence microscopy $\bullet$ high throughput screening

[1] a) M. G. Daidone, R. Silvestrini, J. Natl. Cancer Inst. Monogr. 2001, 27-35; b) S. H. Torp, C. F. Lindboe, U. S. Granli, T. M. Moen, T. Nordtomme, Clin. Neuropathol. 2001, 20, 190-195; c) M. A. Aleskandarany, A. R. Green, A. A. Benhasouna, F. F. Barros, K. Neal, J. S. Reis-Filho, I. O. Ellis, E. A. Rakha, Breast Cancer Res. 2012, 14, R3; dM. Wang, J. Wu, Y. Guo, X. Chang, T. Cheng, Mol Med Rep 2017, 15, 1607-1612; e) T. Wieder, E. Brenner, H. Braumuller, O. Bischof, M. Rocken, Cancer Metastasis Rev. 2017; f) A. S. Thorat, N. A. Sonone, V. V. Choudhari, R. M. Devarumath, K. H. Babu, 3 Biotech. 2017, 7, 16; g) H. Chen, X. Gu, Y. Liu, J. Wang, S. E. Wirt, R. Bottino, H. Schorle, J. Sage, S. K. Kim, Nature 2011, 478, 349-355; h) K. D. Poss, L. G. Wilson, M. T. Keating, Science 2002, 298, 2188-2190.

[2] a) X. Lu, J. W. Horner, E. Paul, X. Shang, P. Troncoso, P. Deng, S. Jiang, Q. Chang, D. J. Spring, P. Sharma, J. A. Zebala, D. Y. Maeda, Y. A. Wang, R. A DePinho, Nature 2017, 543, 728-732; b) N. V. Jordan, A. Bardia, B. S. Wittner, C. Benes, M. Ligorio, Y. Zheng, M. Yu, T. K. Sundaresan, J. A. Licausi, R. Desai, R. M. O'Keefe, R. Y. Ebright, M. Boukhali, S. Sil, M. L. Onozato, A. J. lafrate, R. Kapur, D. Sgroi, D. T. Ting, M. Toner, S. Ramaswamy, W. Haas, S. Maheswaran, D. A. Haber, Nature 2016, 537, 102-106; c) M. A. Erb, T. G. Scott, B. E. Li, H. Xie, J. Paulk, H. S. Seo, A. Souza, J. M. Roberts, S. Dastjerdi, D. L. Buckley, N. E. Sanjana, O. Shalem, B. Nabet, R. Zeid, N. K. Offei-Addo, S. Dhe-Paganon, F. Zhang, S. H. Orkin, G. E. Winter, J. E. Bradner, Nature 2017, $543,270-274$.

[3] a) G. I. Evan, K. H. Vousden, Nature 2001, 411, 342-348; b) G. Evan, T. Littlewood Science 1998, 281, 1317-1322

[4] a) A. Salic, T. J. Mitchison, Proc. Natl. Acad. Sci. U. S. A. 2008, 105, 2415-2420; b) M. Ababou, V. Dumaire, Y. Lecluse, M. Amor-Gueret, Oncogene 2002, 21, 2079-2088; c) B. L. Cavanagh, T. Walker, A. Norazit, A. C. Meedeniya, Molecules 2011, 16, 7980-7993.

[5] a) H. C. Kolb, M. G. Finn, K. B. Sharpless, Angew. Chem. Int .Ed. 2001, 40, 2004-2021; b) P. M. Gramlich, C. T. Wirges, A. Manetto, T. Carell, Angew. Chem. Int. Ed. 2008, 47, 8350-8358.

[6] J. Gierlich, G. A. Burley, P. M. Gramlich, D. M. Hammond, T. Carell, Org. Lett. 2006, 8, 3639-3642.

[7] S. Nik-Zainal, P. Van Loo, D. C. Wedge, L. B. Alexandrov, C. D. Greenman, K. W. Lau, K. Raine, D. Jones, J. Marshall, M. Ramakrishna, A. Shlien, S. L. Cooke, J. Hinton, A. Menzies, L. A. Stebbings, C. Leroy, M. Jia, R. Rance, L. J. Mudie, S. J. Gamble, P. J. Stephens, S. McLaren, P. S. Tarpey, E. Papaemmanuil, H. R. Davies, I. Varela, D. J. McBride, G. R. Bignell, K. Leung, A. P. Butler, J. W. Teague, S. Martin, G. Jonsson, O. Mariani, S. Boyault, P. Miron, A. Fatima, A. Langerod, S. A. Aparicio, A. Tutt, A. M. Sieuwerts, A. Borg, G. Thomas, A. V. Salomon, A. L. Richardson, A. L. Borresen-Dale, P. A. Futreal, M. R. Stratton, P. J. Campbell, C. Breast Cancer Working Group of the International Cancer Genome, Cell 2012, $149,994-1007$.

[8] F. Zanella, J. B. Lorens, W. Link, Trends in Biotechnology, 28, 237-245. 


\section{Supporting information}

Supplementary figures and text:

\begin{tabular}{|l|l|}
\hline Supplementary figure S1 & Synthesis of Tetraazide 1 \\
\hline Supplementary figure S2 & Synthesis of Tetraalkyne 2 \\
\hline Supplementary figure S3 & $\begin{array}{l}\text { Reaction between oligonucleotides and the } \\
\text { tetraazide dendrimer and possible products }\end{array}$ \\
\hline Supplementary figure S4 & $\begin{array}{l}\text { Development of the double click assay (simple } \\
\text { dendrimer) }\end{array}$ \\
\hline Supplementary figure S5 & $\begin{array}{l}\text { Improvement of the signal to background ratio of } \\
\text { the double click assay } \\
\text { Development of the triple click assay (double } \\
\text { dendrimer) }\end{array}$ \\
\hline Supplementary figure S6 & $\begin{array}{l}\text { Direct comparison between the non-dendrimer, the } \\
\text { double and triple click dendrimer approaches }\end{array}$ \\
\hline Supplementary figure S7
\end{tabular}




\section{General methods}

Chemicals were purchased from Sigma-Aldrich, Alfa Aesar, TCI Chemicals or Acros Organics and used without further purification. Solutions were concentrated in vacuo on a Heidolph rotary evaporator. The solvents were of reagent grade and purified by distillation. Dry solvents were bought from Acros Organics or Sigma-Aldrich. Water was purified by a Milli-Q Plus system from Merck Millipore. Chromatographic purification of products was accomplished using flash column chromatography on Merck Geduran Si $60 \quad(40-63 \mu \mathrm{M})$ silica gel (normal phase). Thin layer chromatography (TLC) was performed on Merck 60 (silica gel F254) plates. ${ }^{1} \mathrm{H}$ and ${ }^{13} \mathrm{C}$-NMR spectra were recorded in deuterated solvents on a Bruker ARX 400 spectrometer and calibrated to the residual solvent peak. Multiplicities are abbreviated as follows: $\mathrm{s}=$ singlet, $\mathrm{d}=$ doublet, $\mathrm{t}=$ triplet, $\mathrm{q}=$ quartet, $\mathrm{m}=$ multiplet, brs = broad signal. For assignment of the structures, additional 2D NMR spectra (COSY, HSQC, HMBC) were measured. High resolution electrospray ionization mass spectra (HRMS-ESI) were recorded on a Thermo Finnigan LTQ-FT (ESI-FTICR).

DNA Oligonucleotide synthesis was performed on an Applied Biosystems Incorporated 394 automated synthesizer. Phosphoramidites and solid supports columns were purchased from Glen Research, Link Technology or Baseclick.

Analytical RP-HPLC was performed using a Macherey-Nagel Nucleodur 100-3 C18ec column on Waters Alliance 2996 Photodiode Array Detector, 2695 Separation Module using a flow of $0.5 \mathrm{~mL} / \mathrm{min}$. Conditions: Buffer $\mathrm{A}=0.1 \mathrm{M}$ TEAA (triethylammonium acetate) in water; buffer $B=0.1 \mathrm{M}$ TEAA in $80 \%$ acetonitrile. When needed, the product peaks were collected, concentrated and characterized by Matrix Assisted Laser Desorption Ionization-Time of Flight (MALDI-TOF) on Bruker Daltonics Autoflex II. 


\section{Chemical synthesis}

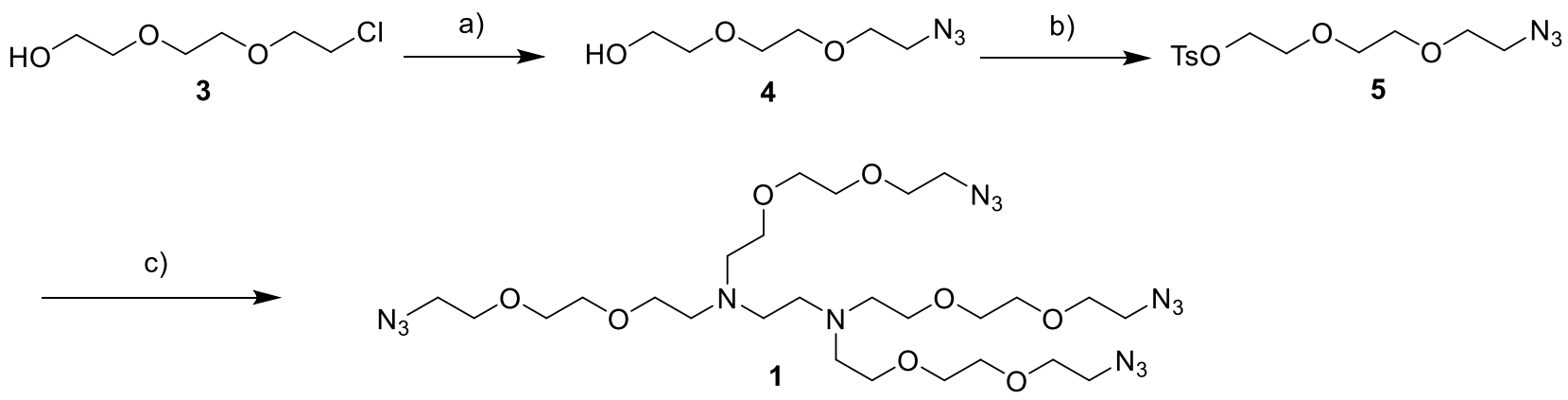

Supplementary figure S1: Synthesis of 1 . Reagents and conditions: a) $\mathrm{NaN}_{3}$, DMF, $90^{\circ} \mathrm{C}$ o/n, 96\%; b) TsCl, $\mathrm{NEt}_{3}, \mathrm{CH}_{2} \mathrm{Cl}_{2}$, o/n, 90\%; c) 5, ethylenediamine, $\mathrm{KOH}, \mathrm{LiBr}$, DMF, $60^{\circ} \mathrm{C}, \mathrm{o} / \mathrm{n}, 63 \%$.

\section{2-[2-(2-Azidoethoxy)ethoxy]ethanol (4)}

2-[2-(2-Chloroethoxy)ethoxy]ethanol (3) $(4.31 \mathrm{~mL}, 29.65 \mathrm{mmol})$ was dissolved in 200 $\mathrm{mL}$ of dry DMF under $\mathrm{N}_{2} . \mathrm{NaN}_{3}$ (3.86 g, $59.3 \mathrm{mmol}$ ) was added, and the mixture was heated at $90^{\circ} \mathrm{C}$ overnight. After $18 \mathrm{~h}$, the solvent was removed under reduced pressure and the residue was partitioned between $\mathrm{H}_{2} \mathrm{O}(50 \mathrm{~mL})$ and EtOAc $(150 \mathrm{~mL})$. The aqueous phase was extracted again with $150 \mathrm{~mL}$ of EtOAc and the combined organic phases were combined, washed with brine, dried over $\mathrm{Na}_{2} \mathrm{SO}_{4}$, filtered and evaporated. The crude product was purified by column chromatography (isohexane/EtOAc 1:4 $\rightarrow$ 1:10) to afford 4 as a colorless oil (5.0 g, 96\%).

${ }^{1} \mathrm{H}$ NMR $\left(400 \mathrm{MHz}, \mathrm{CDCl}_{3}\right) \delta 3.77-3.71(\mathrm{~m}, 2 \mathrm{H}), 3.68(\mathrm{~s}, 6 \mathrm{H}), 3.62-3.58(\mathrm{~m}, 2 \mathrm{H})$, 3.43-3.37 (m, 2H) ppm.

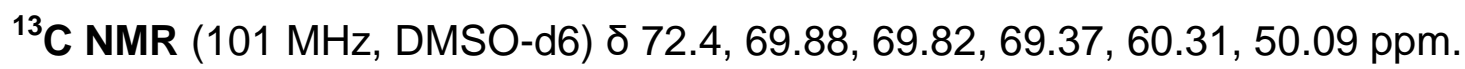

\section{2-(2-(2-Azidoethoxy)ethoxy)ethyl 4-methylbenzenesulfonate (5)}

Compound 4 (5 g, $28.54 \mathrm{mmol}$ ) was dissolved in $100 \mathrm{~mL}$ of DCM at room temperature. The solution was then cooled to $0^{\circ} \mathrm{C}$ and $\mathrm{NEt}_{3}$ and $\mathrm{TsCl}$ were added. The mixture was then stirred overnight allowing to warm up to room temperature. After 18 hours, the reaction mixture was washed with $1 \mathrm{M} \mathrm{HCl}, \mathrm{H}_{2} \mathrm{O}$, brine, dried over $\mathrm{MgSO}_{4}$ and filtered. The solvent was removed under reduced pressure and the crude product was purified by column chromatography (isohexane/EtOAc 10:1) to yield $\mathbf{5}$ as a colourless oil $(8.5 \mathrm{~g}, 90 \%)$. 
${ }^{1} \mathrm{H}$ NMR $\left(400 \mathrm{MHz}, \mathrm{CDCl}_{3}\right) \delta 7.77(\mathrm{~d}, \mathrm{~J}=8 \mathrm{~Hz}, 2 \mathrm{H}), 7.32(\mathrm{~d}, \mathrm{~J}=8 \mathrm{~Hz}, 2 \mathrm{H}), 4.13(\mathrm{t}, \mathrm{J}=$ $6 \mathrm{~Hz}, 2 \mathrm{H}), 3.70-3.55(\mathrm{~m}, 8 \mathrm{H}), 3.34(\mathrm{t}, \mathrm{J}=5 \mathrm{~Hz}, 2 \mathrm{H}), 2.42(\mathrm{~s}, 3 \mathrm{H}) \mathrm{ppm}$.

\section{N1,N1,N2,N2-Tetrakis(2-(2-(2-azidoethoxy)ethoxy)ethyl)ethane-1,2-diamine (tetraazide dendrimer 1 )}

Ethylenediamine (150 mg, $167 \mu \mathrm{L}, 1.66 \mathrm{mmol}$ ) was dissolved in $50 \mathrm{~mL}$ of dry DMF. $\mathrm{KOH}(613 \mathrm{mg}, 10.8 \mathrm{mmol})$ and $\mathrm{LiBr}$ were added at RT. Compound 5 was then added dropwise as a solution in $20 \mathrm{~mL}$ of DMF, then the reaction was stirred for 2 hours at $\mathrm{RT}$ and heated at $60^{\circ} \mathrm{C}$ overnight. After 20 hours, the solvent was removed under vacuum and the residue was retaken in EtOAc, washed with sat. $\mathrm{NaHCO}_{3}$, brine, dried over $\mathrm{Na}_{2} \mathrm{SO}_{4}$ and filtered. Evaporation of the solvent afforded a yellowish oil that was purified by column chromatography (DCM/MeOH 30:1 $\rightarrow 10: 1) .1 .1 \mathrm{~g}$ of product was recovered (63\%).

HR-MS (ESI+): calculated for $\mathrm{C}_{26} \mathrm{H}_{53} \mathrm{~N}_{14} \mathrm{O}_{8}{ }^{+} 689.4165$, found: 689.4159 .

${ }^{1} \mathrm{H}$ NMR $\left(400 \mathrm{MHz}, \mathrm{CD}_{3} \mathrm{CN}\right) \delta 3.58\left(\mathrm{t}, \mathrm{J}=6 \mathrm{~Hz}, 8 \mathrm{H}, 4 \times \mathrm{N}_{3} \mathrm{CH}_{2} \mathrm{C}_{2} \mathrm{OR}\right)$, 3.57-3.42 (m, 24H),3.32 (t, J=5 Hz, 8H, 4x N ${ }_{3} \mathrm{CH}_{2} \mathrm{CH}_{2} \mathrm{OR}$ ) 2.82-2.48 (brs, $12 \mathrm{H}$, $\left.\left(\mathrm{RC}_{2}\right)_{2} \mathrm{NC}_{2} \underline{\mathrm{CH}}_{2} \mathrm{~N}\left(\mathrm{C}_{2}\right)_{2}\right) \mathrm{ppm}$.

${ }^{13} \mathrm{C}$ NMR $\left(101 \mathrm{MHz}, \mathrm{CD}_{3} \mathrm{CN}\right) \delta 71.07,71.02,70.47,70.19,54.99,53.83,51.43$ 


\section{NMR spectra of 1}
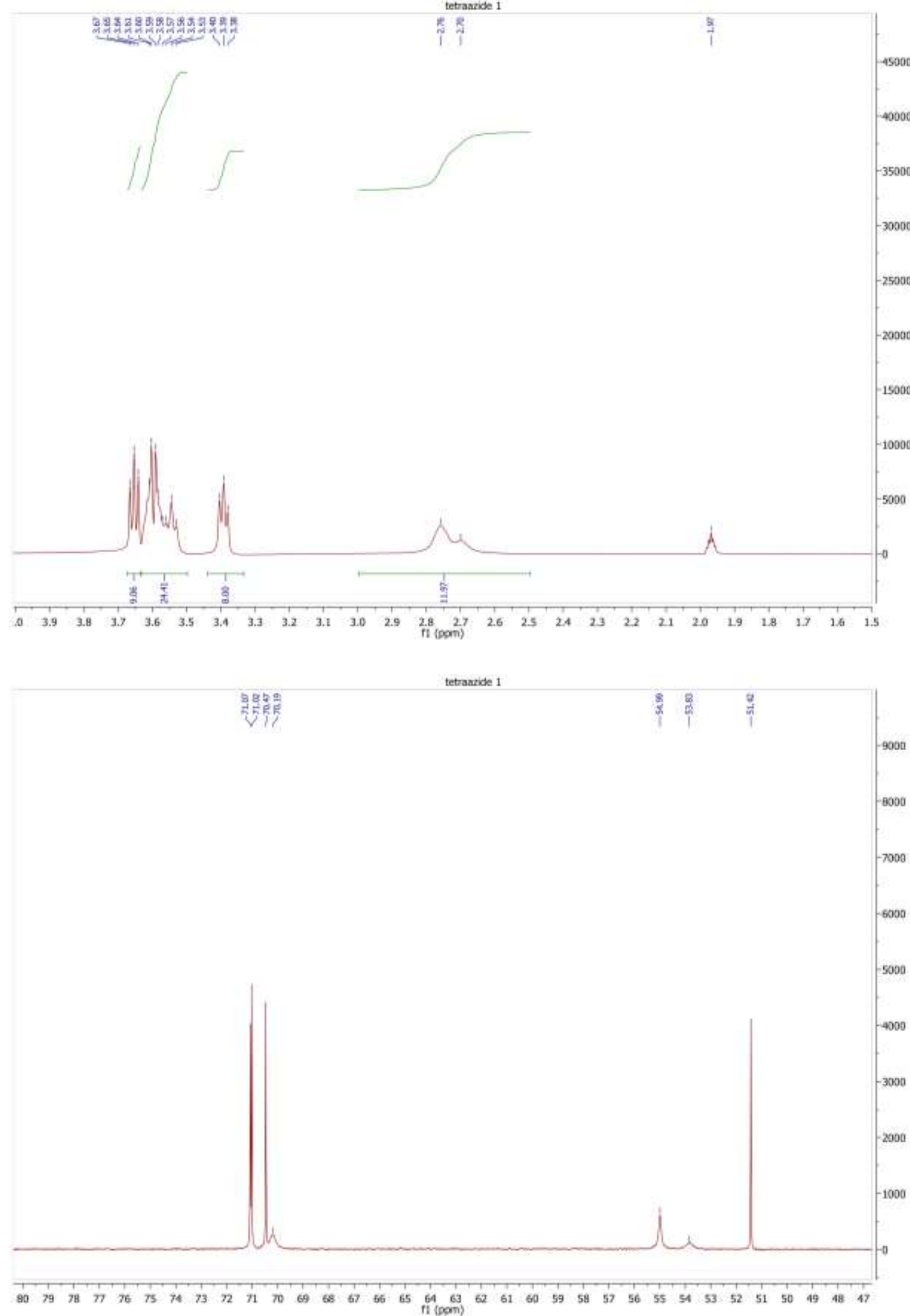


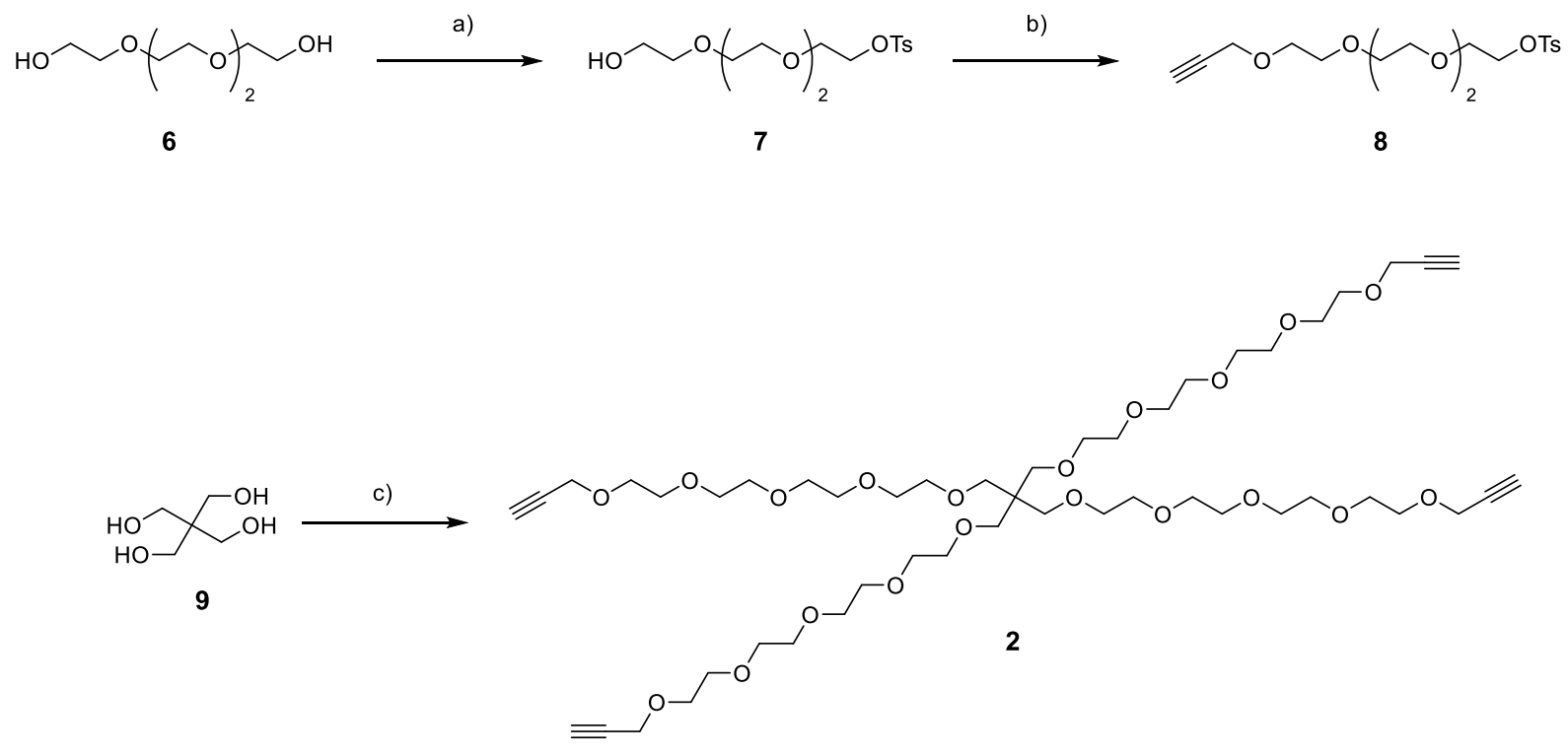

Supplementary figure S2: Synthesis of 2. Reagents and conditions: a) $\mathrm{TsCl}_{1} \mathrm{Et}_{3} \mathrm{~N}$, THF, RT, 48 h, $92 \%$; b) Propargyl bromide, $\mathrm{NaH}, \mathrm{THF}, 0^{\circ} \mathrm{C}$ to RT, $82 \%$; c) 1, $\mathrm{K}_{2} \mathrm{CO}_{3}$, acetone, $60^{\circ} \mathrm{C}, 48 \mathrm{~h}, 30 \%$.

\section{2-(2-(2-(2-hydroxyethoxy)ethoxy)ethoxy)ethyl 4-methylbenzenesulfonate (7)}

Tetraethylene glycol $(29.25 \mathrm{~g}, 150.6 \mathrm{mmol})$ was dissolved in dry THF (100 mL) and triethylamine (122 g, $1.2 \mathrm{~mol}, 8.0 \mathrm{eq}$.) was added. The reaction was cooled down to $0^{\circ} \mathrm{C}$ and a solution of tosyl chloride $(28.71 \mathrm{~g}, 150.6 \mathrm{mmol}, 1.0$ eq.) in dry THF (50 mL) was added over a period of $1 \mathrm{~h}$. After $48 \mathrm{~h}$ stirring at room temperature the solvent was removed in vacuo. The mixture was taken up in $\mathrm{HCl}(2 \mathrm{M}, 150 \mathrm{~mL})$ and extracted with DCM $(4 \times 150 \mathrm{~mL})$. The combined organic layers were dried over $\mathrm{MgSO}_{4}$ and filtered. After removal of the solvent in vacuo the crude product was purified by flash chromatography (Silica, DCM $\rightarrow \mathrm{DCM} / \mathrm{MeOH}(99: 1 \rightarrow 0: 1)$ ). The product was obtained as a colourless oil $(48.27 \mathrm{~g}, 138.6 \mathrm{mmol}, 92 \%)$.

${ }^{1} \mathrm{H}-\mathrm{NMR}\left(400 \mathrm{MHz}, \mathrm{CDCl}_{3}\right): \delta=7.82-7.76\left(\mathrm{~m}, 2 \mathrm{H}, \mathrm{CH}_{\text {arom. }}\right)$, 7.37-7.30 (m, $2 \mathrm{H}$, $\left.\mathrm{CH}_{\text {arom. }}\right)$, 4.20-4.12 (m, $\left.2 \mathrm{H}, \mathrm{CH}_{2}\right), 3.73-3.52\left(\mathrm{~m}, 14 \mathrm{H}, 7 \times \mathrm{CH}_{2}\right), 2.42\left(\mathrm{~s}, 3 \mathrm{H}, \mathrm{CH}_{3}\right), 2.38-$ $2.31(\mathrm{~s}, 1 \mathrm{H}, \mathrm{OH}) \mathrm{ppm}$.

${ }^{13} \mathrm{C}$-NMR (100 MHz, $\left.\mathrm{CDCl}_{3}\right): \delta=144.9$ (C $\mathrm{C}$ arom.), 133.2 ( $\left.\mathrm{C}_{\text {arom. }}\right), 130.0\left(2 \times \mathrm{CH}_{\text {arom. }}\right)$, $128.1\left(2 \times \mathrm{CH}_{\text {arom. }}\right), 72.6\left(\mathrm{CH}_{2}\right), 70.9\left(\mathrm{CH}_{2}\right), 70.8\left(\mathrm{CH}_{2}\right), 70.6\left(\mathrm{CH}_{2}\right), 70.5\left(\mathrm{CH}_{2}\right), 69.4$ $\left(\mathrm{CH}_{2}\right), 68.9\left(\mathrm{CH}_{2}\right), 61.9\left(\mathrm{CH}_{2}\right), 21.8\left(\mathrm{CH}_{3}\right)$ ppm.

HR-MS (ESI): $\mathrm{C}_{15} \mathrm{H}_{25} \mathrm{O}_{7} \mathrm{~S}^{+}[\mathrm{M}+\mathrm{H}]^{+}$, calc.: 349.1315 , found: 349.1316 


\section{3,6,9,12-tetraoxapentadec-14-yn-1-yl 4-methylbenzenesulfonate (8)}

2-(2-(2-(2-hydroxyethoxy)ethoxy)ethoxy)ethyl 4-methylbenzenesulfonate $(10 \mathrm{~g}, 28.7$ $\mathrm{mmol}$ ) was dissolved in dry THF $(50 \mathrm{~mL})$ and added dropwise to a solution of $\mathrm{NaH}$ $\left(60 \%, 1.38 \mathrm{~g}, 34.44 \mathrm{mmol}, 1.2 \mathrm{eq}\right.$.) in dry THF $(50 \mathrm{~mL})$ at $0{ }^{\circ} \mathrm{C}$. Propargylbromide ( $80 \%$ in toluene, $31.85 \mathrm{~mL}, 287 \mathrm{mmol}, 10$ eq.) was subsequently added to the mixture and stirred for $2 \mathrm{~h}$ at RT. The reaction was carefully quenched by slow addition of $\mathrm{MeOH}$ and the solvents were removed in vacuo. $\mathrm{H}_{2} \mathrm{O}$ was added and extracted with DCM $(3 \times 200 \mathrm{~mL})$. The combined organic layers were dried over $\mathrm{MgSO}_{4}$, the solvent removed in vacuo and the crude product was purified by column chromatography (Silica, DCM $\rightarrow \mathrm{DCM} / \mathrm{MeOH}(99: 1 \rightarrow 0: 1)$ ). X was obtained as a colorless oil (9.06 g, $23.4 \mathrm{mmol}, 82 \%)$.

${ }^{1} \mathrm{H}-\mathrm{NMR}\left(400 \mathrm{MHz}, \mathrm{CDCl}_{3}\right): \delta=7.81-7.78\left(\mathrm{~m}, 2 \mathrm{H}, \mathrm{CH}_{\text {arom. }}\right)$, 7.35-7.33 (m, $2 \mathrm{H}$, $\left.\mathrm{CH}_{\text {arom. }}\right), 4.21-4.18\left(\mathrm{~m}, 2 \mathrm{H}, \mathrm{CH}_{2}\right), 4.17-4.14\left(\mathrm{~m}, 2 \mathrm{H}, \mathrm{CH}_{2}\right), 3.70-3.56\left(\mathrm{~m}, 14 \mathrm{H}, 7 \times \mathrm{CH}_{2}\right)$, $2.44\left(\mathrm{~s}, 3 \mathrm{H}, \mathrm{CH}_{3}\right), 2.42(\mathrm{~m}, 1 \mathrm{H}, \mathrm{CH}) \mathrm{ppm}$.

${ }^{13}$ C-NMR (100 MHz, $\left.\mathrm{CDCl}_{3}\right): \delta=145.0$ ( $\left.\mathrm{C}_{\text {arom. }}\right), 133.1$ ( $\left.\mathrm{C}_{\text {arom. }}\right), 130.0\left(2 \times \mathrm{CH}_{\text {arom. }}\right)$, 128.1 (2× $\left.\mathrm{CH}_{\text {arom. }}\right), 78.8(\mathrm{HC} \equiv \mathrm{C}), 75.2(\mathrm{HC} \equiv \mathrm{C}), 70.8\left(\mathrm{CH}_{2}\right), 70.7\left(\mathrm{CH}_{2}\right), 69.4\left(\mathrm{CH}_{2}\right)$, $68.8\left(\mathrm{CH}_{2}\right), 67.7\left(\mathrm{CH}_{2}\right), 56.6\left(\mathrm{CH}_{2}\right), 55.9\left(\mathrm{CH}_{2}\right), 55.4\left(\mathrm{CH}_{2}\right), 21.8\left(\mathrm{CH}_{3}\right)$ ppm.

HR-MS (ESI): $\mathrm{C}_{18} \mathrm{H}_{30} \mathrm{O}_{7} \mathrm{NS}^{+}[\mathrm{M}+\mathrm{NH} 4]^{+}$, calc.: 404.1737 , found: 404.1739 .

\section{8,18-di(2,5,8,11,14-pentaoxaheptadec-16-yn-1-yl)-4,7,10,13,16,20,23,26,29,32- decaoxapentatriaconta-1,34-diyne (2)}

Pentaerythritole (15 mg, $110.18 \mu \mathrm{mol})$ was dissolved in acetone $(3 \mathrm{~mL}) .3,6,9,12$ tetraoxapentadec-14-yn-1-yl 4-methylbenzenesulfonate (213 mg, $550.9 \mu \mathrm{mol}, 5$ eq.) and $\mathrm{K}_{2} \mathrm{CO}_{3}\left(76 \mathrm{mg}, 550.9 \mu \mathrm{mol}, 5\right.$ eq.) were added. After stirring at $60^{\circ} \mathrm{C}$ for $48 \mathrm{~h}$ the solvent was removed in vacuo. $\mathrm{H}_{2} \mathrm{O}$ was added and extracted with $\mathrm{DCM}(4 \times 20 \mathrm{~mL})$. The combined organic layers were dried over $\mathrm{MgSO}_{4}$, the solvent removed in vacuo and the crude product was purified by column chromatography ((Silica, DCM $\rightarrow$ $\mathrm{DCM} / \mathrm{MeOH}(99: 1 \rightarrow 0: 1)$ ). The product was obtained as a colourless oil (33 mg, 33 $\mu \mathrm{mol}, 30 \%)$. 
${ }^{1} \mathrm{H}-\mathrm{NMR}\left(599 \mathrm{MHz}, \mathrm{CDCl}_{3}\right): \delta=4.22-4.19\left(\mathrm{~d},{ }^{3} \mathrm{~J}=2.4 \mathrm{~Hz}, 8 \mathrm{H}, \mathrm{CH}_{2}\right)$, 3.85-3.40 (m, $\left.72 \mathrm{H}, \mathrm{CH}_{2}\right), 2.51-2.37\left(\mathrm{t},{ }^{4} \mathrm{~J}=2.4 \mathrm{~Hz}, 4 \mathrm{H}, \mathrm{CH}_{2}\right) \mathrm{ppm}$.

${ }^{13} \mathrm{C}$-NMR $\left(151 \mathrm{MHz}, \mathrm{CDCl}_{3}\right): \delta=79.83,74.62,72.61,71.52,71.48,70.85,70.83$, $70.81,70.78,70.75,70.71,70.68,70.59,70.58,70.54,69.29,61.95,58.57,42.87$ ppm.

HR-MS (ESI): $\mathrm{C}_{49} \mathrm{H}_{85} \mathrm{O}_{20} \mathrm{Na}^{2+}[\mathrm{M}+\mathrm{H}+\mathrm{Na}]^{2+}$, calc.: 508.2760 , found: 508.2755 . 
NMR spectra of 2
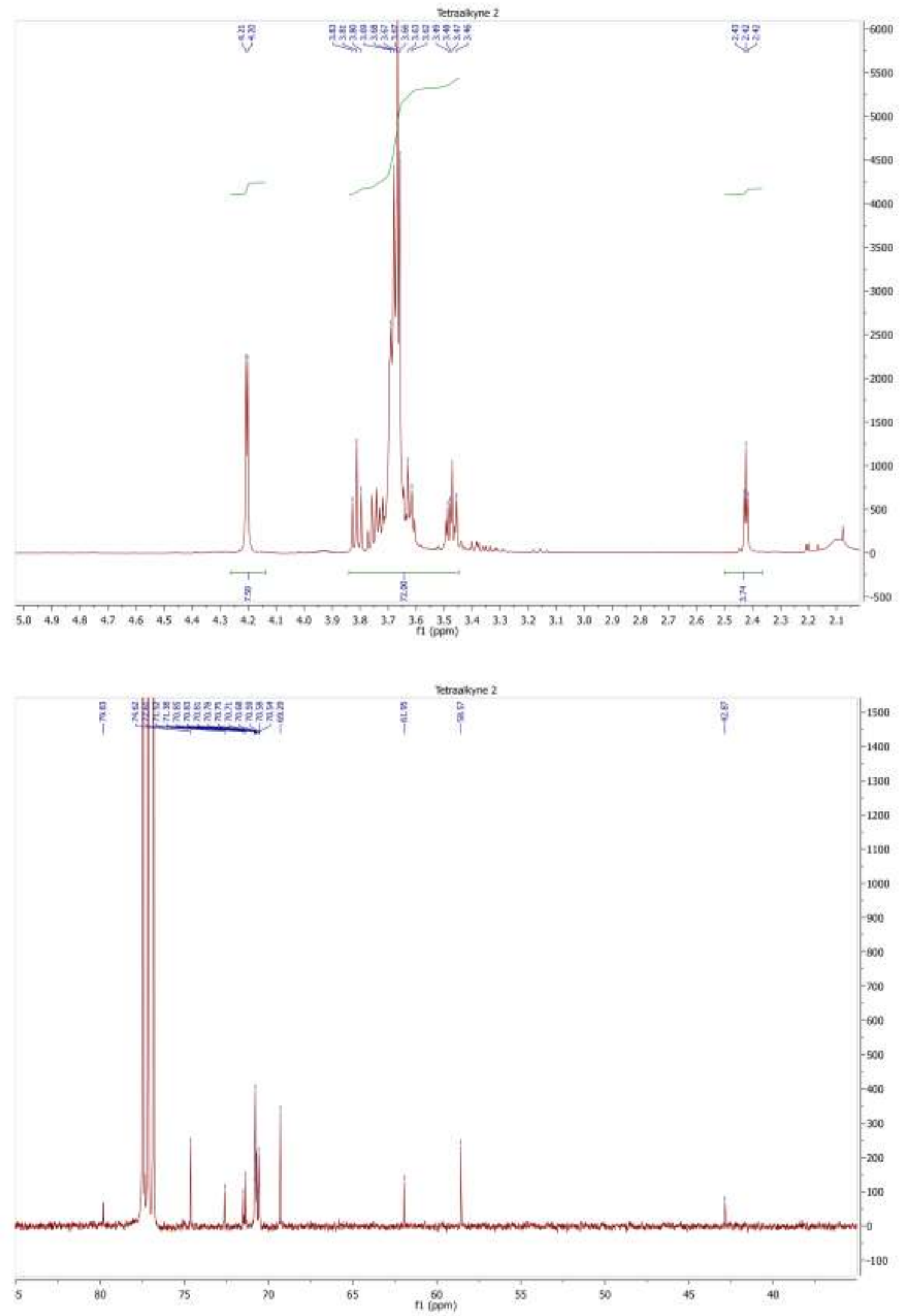


\section{Proof of principle of the click reactions on oligonucleotides}

In order to prove that the strategy that we planned for the in situ detection of cell proliferation using click chemistry is applicable and yields predominantly the products shown in the main text, we performed experiments on synthetic oligonucleotides. We decided to perform the click reactions both in solution, purifying the main intermediates and products via HPLC and on solid phase, where we simply removed the excess of reagents with a few washing steps and then proceeded with the following click reaction. This second approach is more similar to the strategy that we ultimately applied for our cell studies and proved that it is possible to obtain the products that we wanted with good selectivity even without chromatographic purification of the intermediates.

Both pathways were successful and yielded the desired products (oligonucleotide conjugated with multiple dyes) with good selectivity as a mixture of 5/6-TAMRA isomers. As expected, especially for the solid phase reactions, we observed a limited amount of cross-linked compound, where the tetraazide binds two different oligonucleotides in the first step, and therefore can react with only two dyes in the second step (fig. S3).
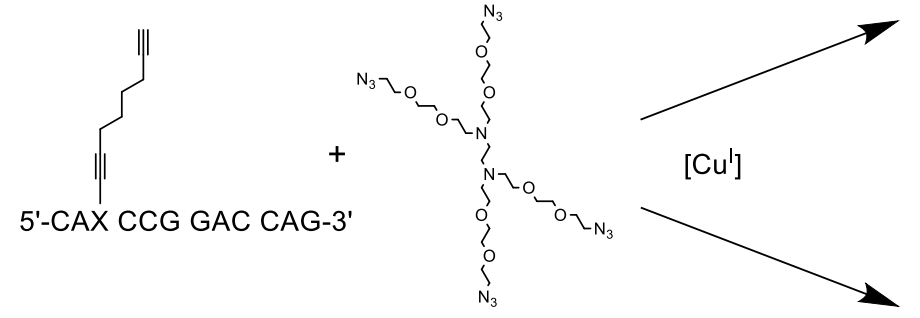

5'-CAX CCG GAC CAG-3'

Maior product
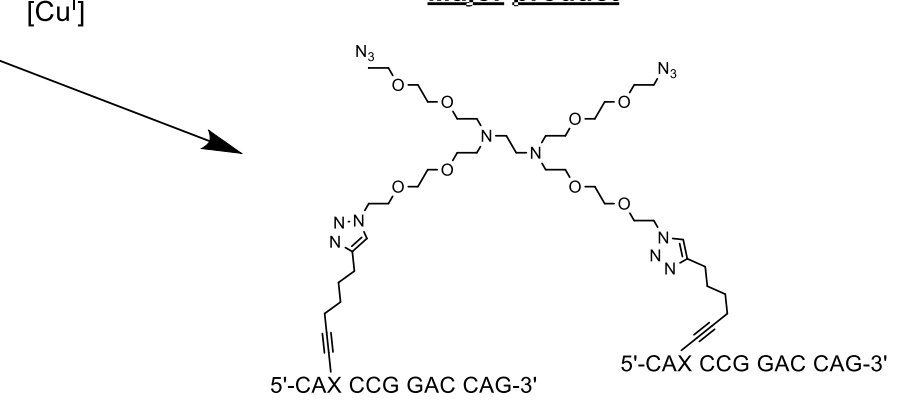

Minor cross-linked product

Supplementary figure S3: Reaction between oligonucleotides and the tetraazidedendrimer and possible products. 


\section{Sequence of the oligonucleotides used for the tests:}

Oligonucleotide 1: 5'- CA $\underline{\mathbf{X}}$ CCG GAC CAG-3' where X = C8-Alkynyl-dT; [M] = 3705.4

Oligonucleotide 2: 5'- TㅁT TTT TTT T -3' where X = EdU; [M] = 2989.9

General procedure A (click in solution): The alkyne-modified oligonucleotide was dissolved in $\mathrm{MQ}$ water (concentration $=1 \mathrm{mM}$ ) and $3 \mu \mathrm{L}$ of this solution $(3 \mathrm{nmol}$ of oligonucleotide) were transferred in a vial for the click reaction. To this solution, $\mathrm{H}_{2} \mathrm{O}$ $(15 \mu \mathrm{L}), 1 \mathrm{M}$ TEAA buffer $(\mathrm{pH} 7,6 \mu \mathrm{L})$, DMSO $(27 \mu \mathrm{L})$ and the azide or dye-alkyne solution ( $20 \mathrm{mM}$ in DMSO, $3 \mu \mathrm{L}$ ) were added. A CuSO ${ }_{4} /$ TBTA solution ( $1 \mathrm{mM}$ in $\mathrm{H}_{2} \mathrm{O}$ /DMSO 1:1, $3 \mu \mathrm{L}$ ) was then added, followed by a freshly prepared solution of sodium ascorbate $(2.5 \mathrm{mM}, 3 \mu \mathrm{L})$. The mixture was then shaken for 1 hour on a Thermomixer at $25^{\circ} \mathrm{C}, 1200 \mathrm{rpm}$, and the solvent was then directly evaporated on a SpeedVac at $35^{\circ} \mathrm{C}$. All the products were analyzed and purified using RP-HPLC and identified using MALDI-TOF-MS.

Cyanoethyl deprotection: After solid phase oligonucleotide synthesis on a $200 \mathrm{nmol}$ scale, part of the resin (approximately $50 \mathrm{nmol}$ of oligonucleotide), was suspended in $500 \mu \mathrm{L}$ of $10 \% \mathrm{DBU}$ in dry acetonitrile to deprotect the cyanoethyl groups on the phosphates. The suspension was shaken on a Thermomixer at $30^{\circ} \mathrm{C}$ for $1 \mathrm{~h}$. After centrifugation, the DBU solution was decanted off and the resin was washed 5 times with $1 \mathrm{~mL}$ of dry acetonitrile.

General procedure $\mathbf{B}$ (click on solid phase): The dried resin was suspended in $375 \mu \mathrm{L}$ of $\mathrm{H}_{2} \mathrm{O} / \mathrm{DMSO} 1: 2$. To this, $1 \mathrm{M}$ TEAA buffer $(\mathrm{pH} 7,100 \mu \mathrm{L})$, the azide or dyealkyne solution (20 mM in DMSO, $50 \mu \mathrm{L}$ ) and the $\mathrm{CuSO}_{4} / \mathrm{TBTA}$ solution ( $1 \mathrm{mM}$ in $\mathrm{H}_{2} \mathrm{O} /$ DMSO $1: 1,25 \mu \mathrm{L}$ ) were added, followed by a freshly prepared solution of sodium ascorbate $(1 \mathrm{mM}, 75 \mu \mathrm{L})$. After $1.5 \mathrm{~h}$ shaking on a Thermomixer at $25^{\circ} \mathrm{C}$, $1200 \mathrm{rpm}$, the mixture was centrifuged and the supernatant was discarded. The resin was then washed with $\mathrm{H}_{2} \mathrm{O}(500 \mu \mathrm{L}), \mathrm{MeCN}(500 \mu \mathrm{L} \times 3)$ and dried.

Standard cleavage procedure: The resin was suspended in $400 \mu \mathrm{L}$ of $28-30 \%$ aqueous ammonium hydroxide and shaken at $30^{\circ} \mathrm{C}$ for $1 \mathrm{~h}$. After centrifugation, the supernatant was collected and the resin washed again with $\mathrm{H}_{2} \mathrm{O}(2 \times 200 \mu \mathrm{L})$. The solution was then evaporated on a SpeedVac at $35^{\circ} \mathrm{C}$ to obtain the products that were analyzed by RP-HPLC and MALDI-TOF-MS and then purified. 
Cleavage procedure for TAMRA-containing oligonucleotides: The resin was suspended in $200 \mu \mathrm{L}$ of a solution of $\mathrm{tBuNH} / \mathrm{MeOH} / \mathrm{H}_{2} \mathrm{O}$ 1:1:3 solution and shaken at $40{ }^{\circ} \mathrm{C}$ for 1 hour. After centrifugation, the resin was washed twice with $200 \mu \mathrm{L}$ of $\mathrm{H}_{2} \mathrm{O}$ and the combined solutions were evaporated on a SpeedVac at $40^{\circ} \mathrm{C}$. The products were analyzed by RP-HPLC and MALDI-TOF-MS.

\section{RP-HPLC chromatograms of the starting materials}

Oligonucleotide 1 (0-70\% B in $45 \mathrm{~min})$

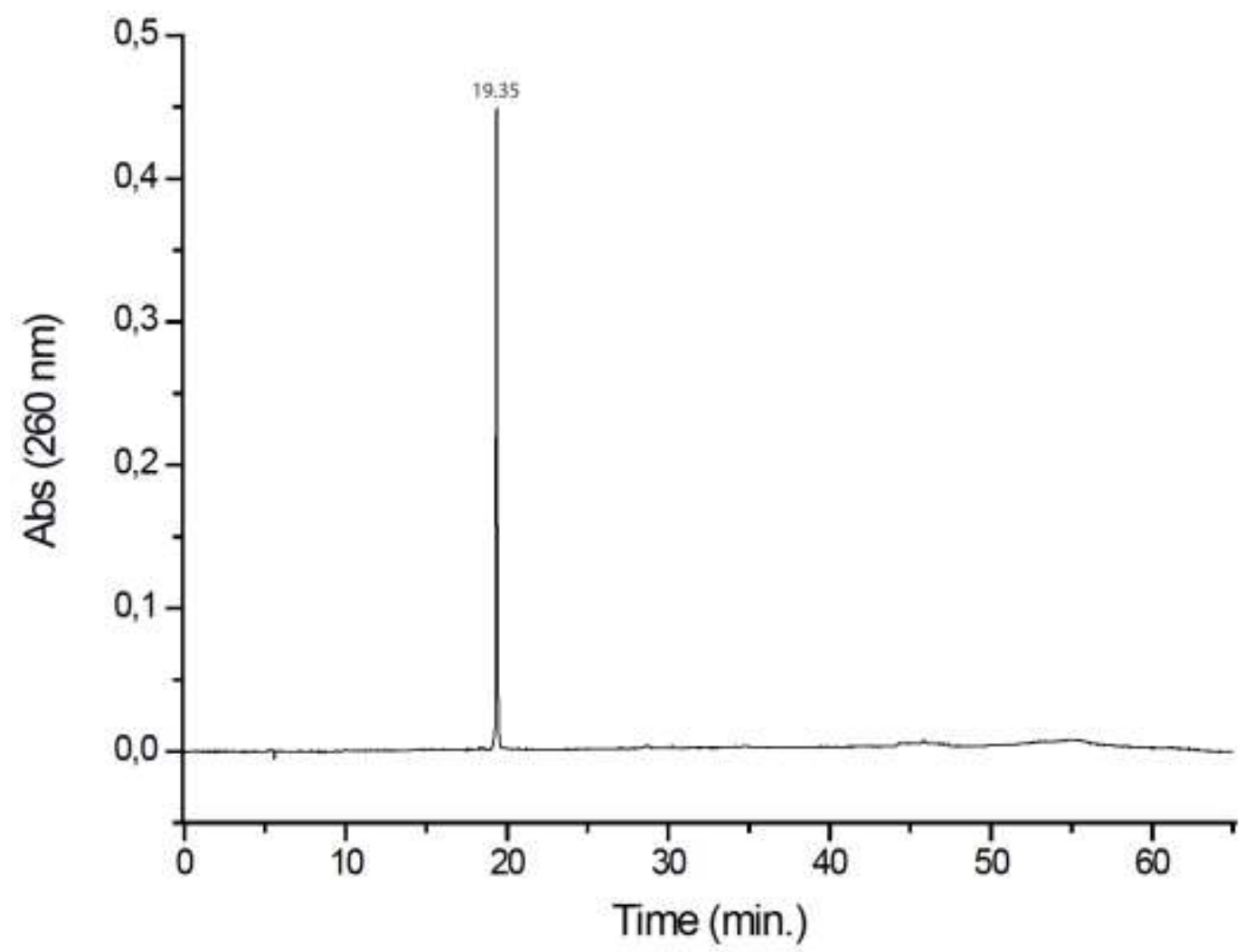


Oligonucleotide 2 (0-70\% B in $33 \mathrm{~min})$

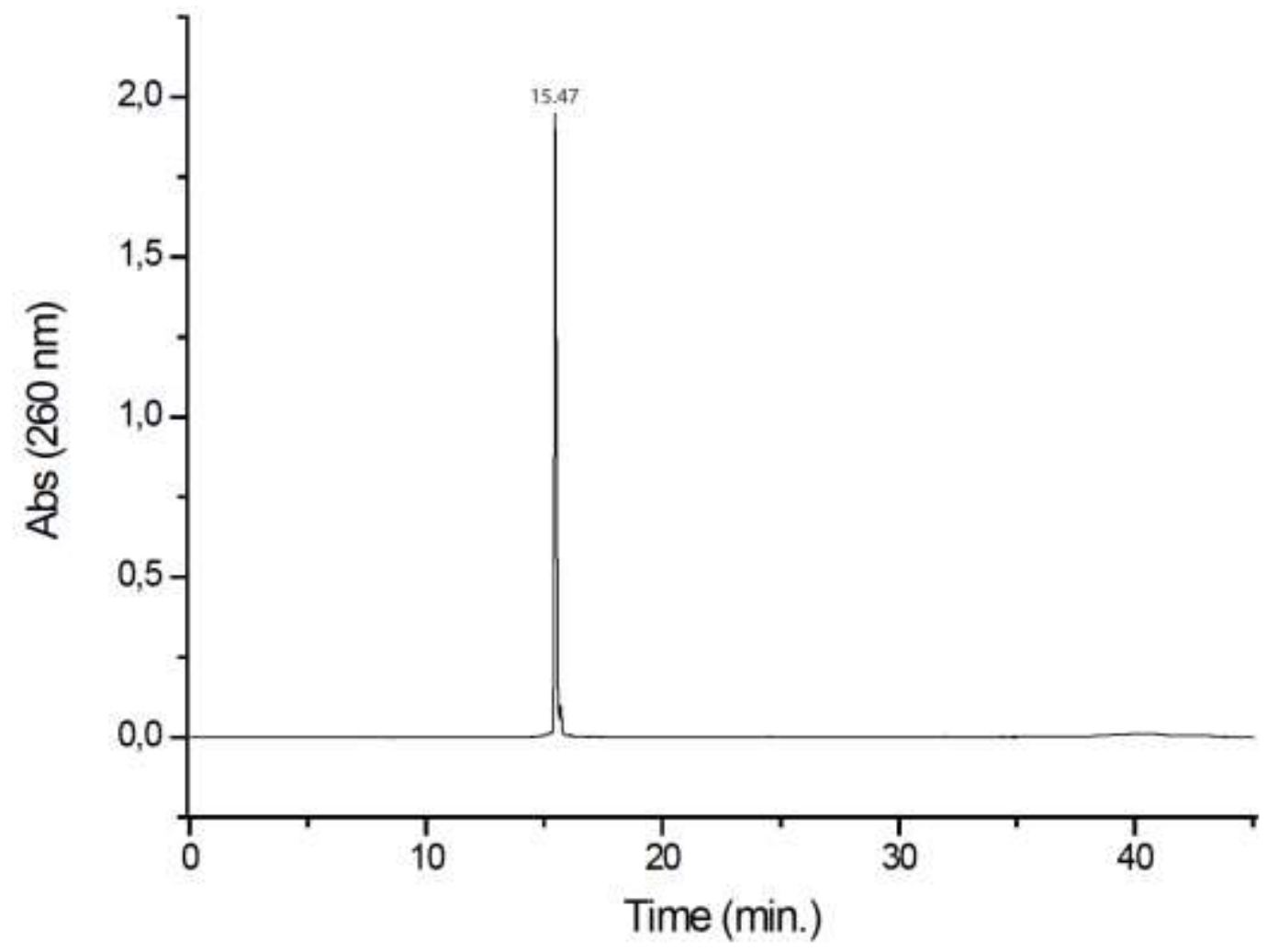

\section{5/6-TAMRA-PEG4-alkyne}

Method $0-70 \%$ B in 45 min (for click reactions in solution)

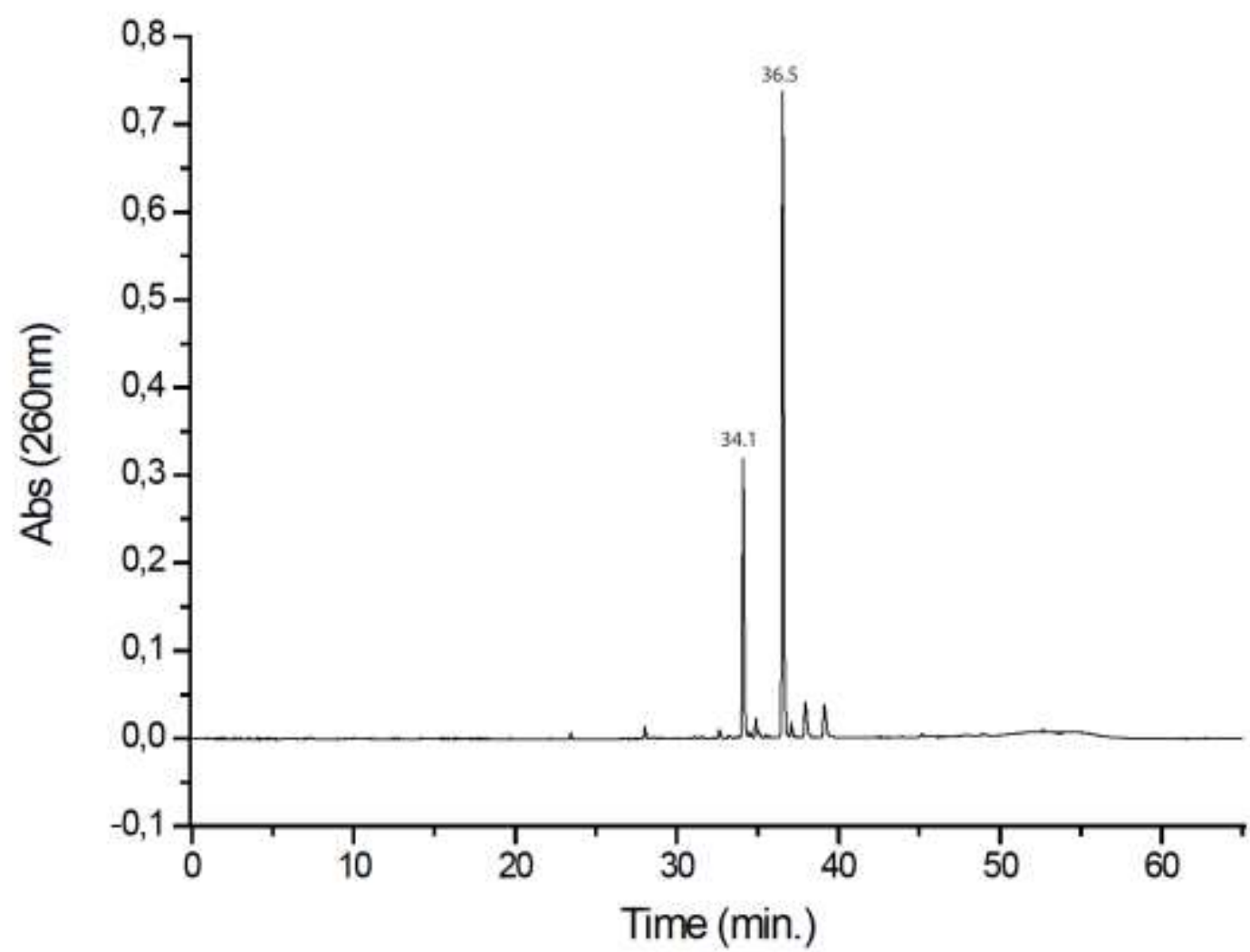




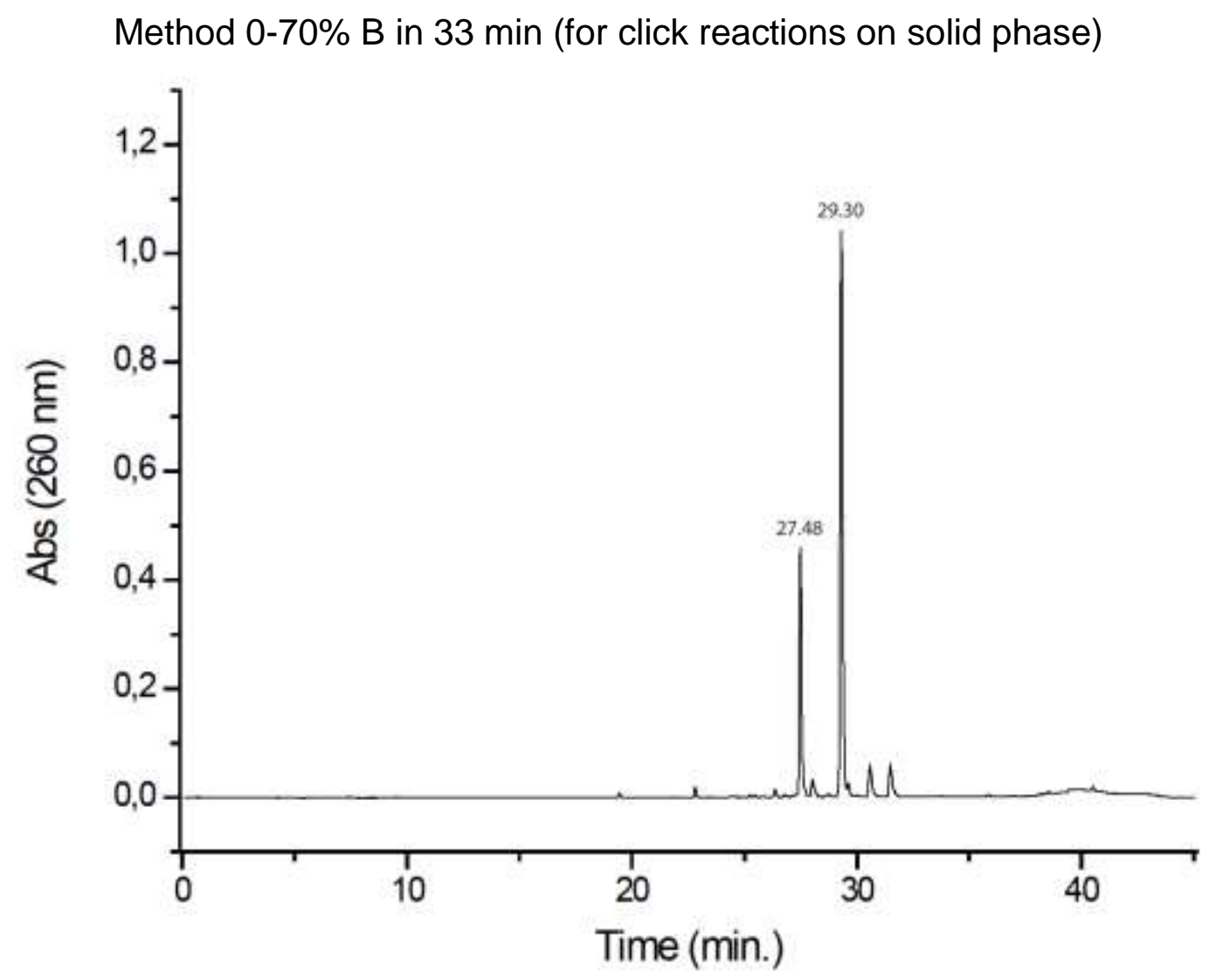

Click 1: Oligonucleotide 1 + tetraazide dendrimer
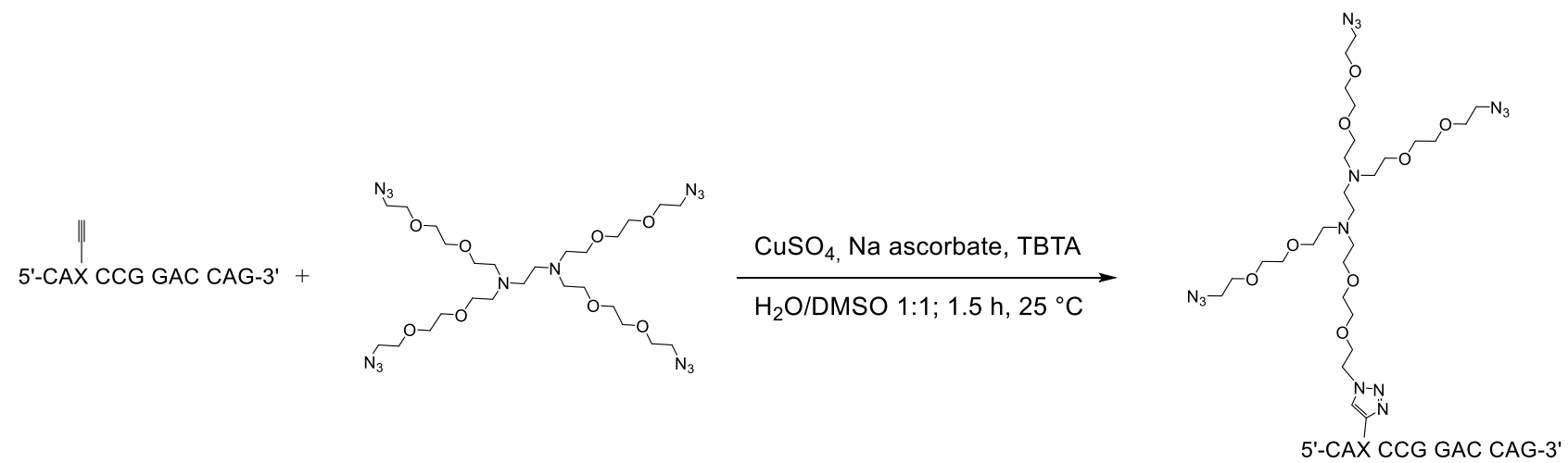

After the click reaction with the oligonucleotide 1 using the general procedure $\mathbf{A}$, analysis via RP-HPLC showed a quantitative conversion of the starting material to the clicked products. 


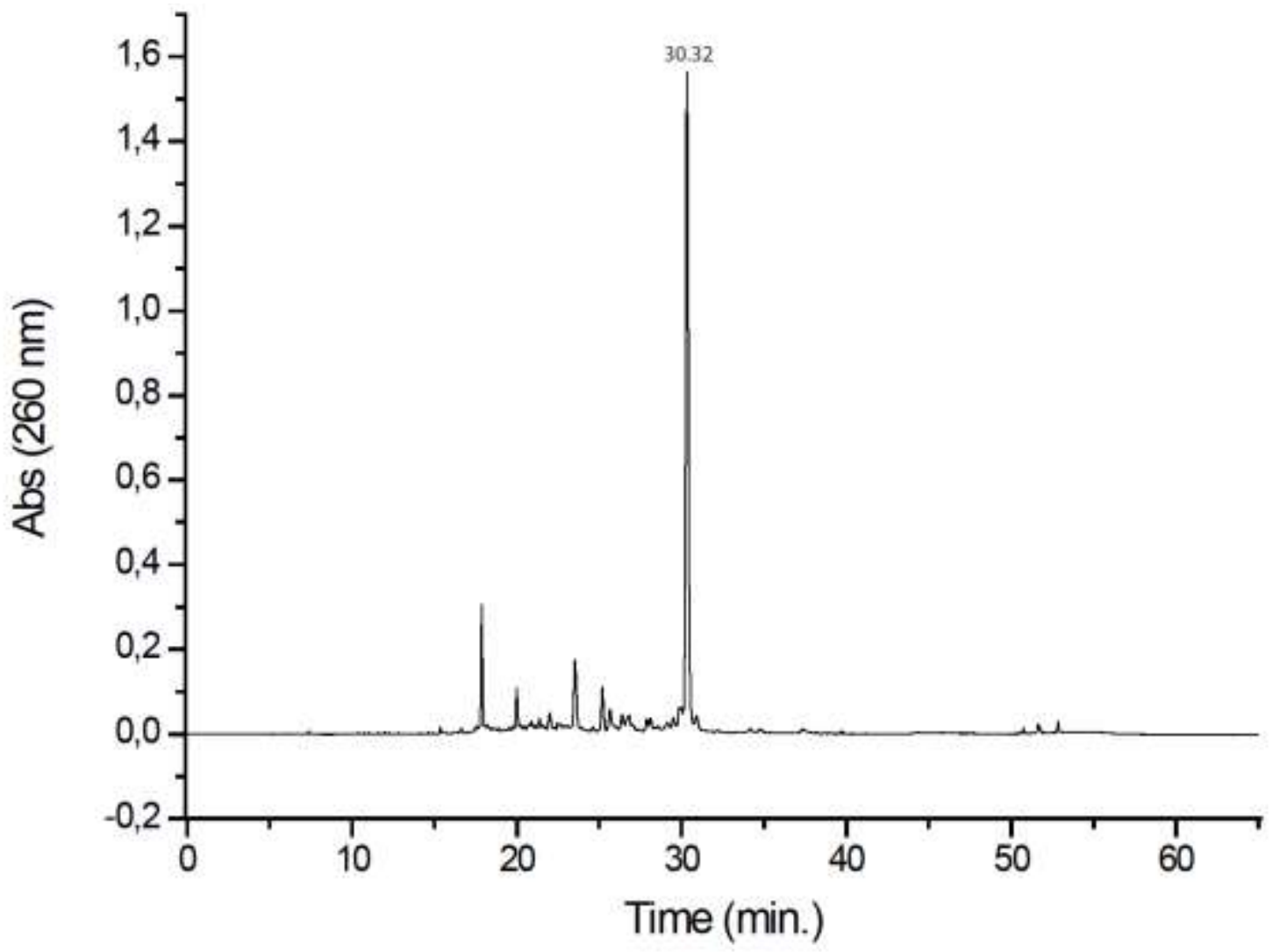

MALDI-TOF-MS: [M] calc. for oligonucleotide $1+$ dendrimer $=4393.8$; found $=$ 4389.5 .

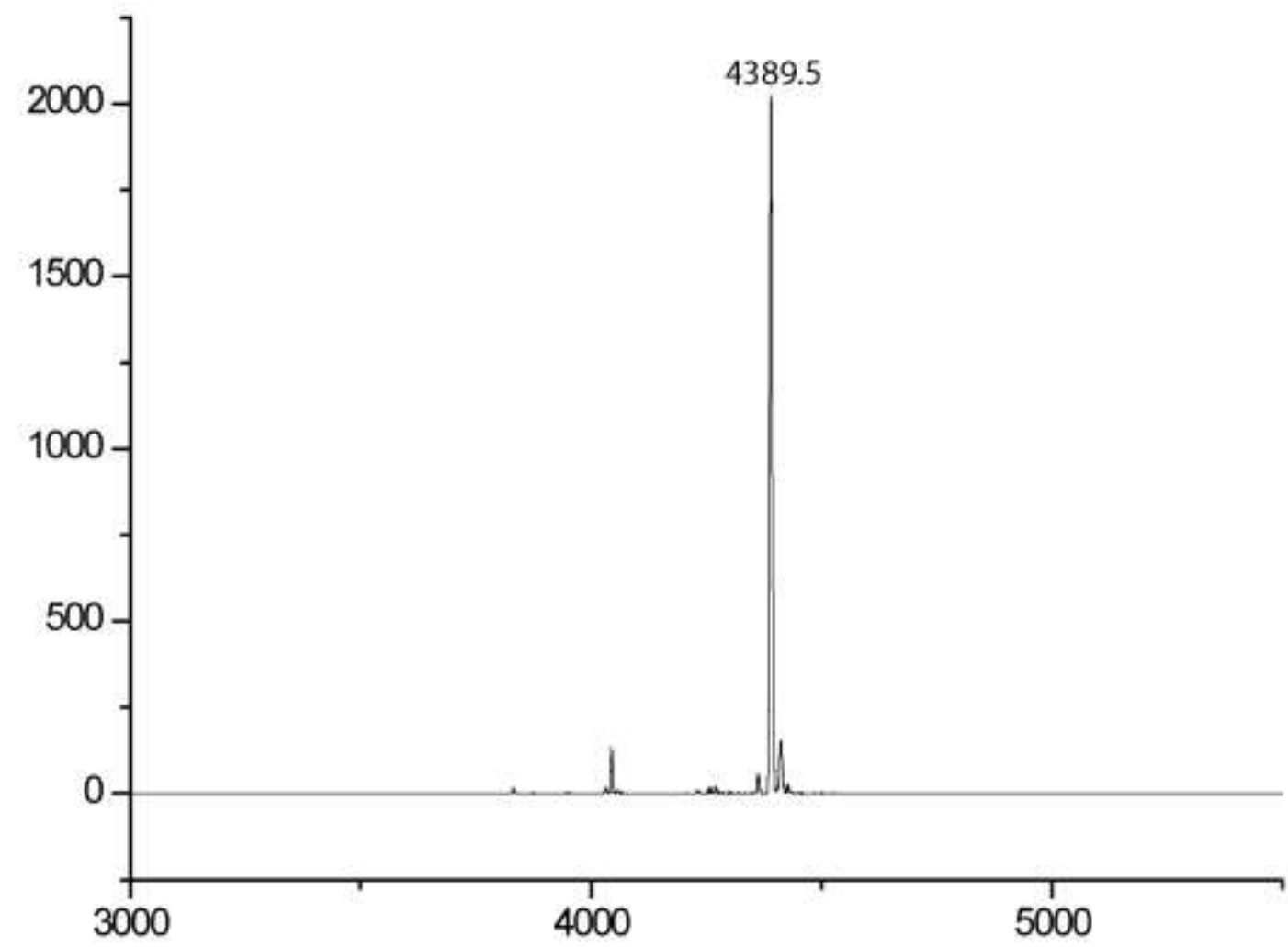




\section{Click 2: Oligonucleotide from Click 1 + 5/6-TAMRA-PEG4-Alkyne}
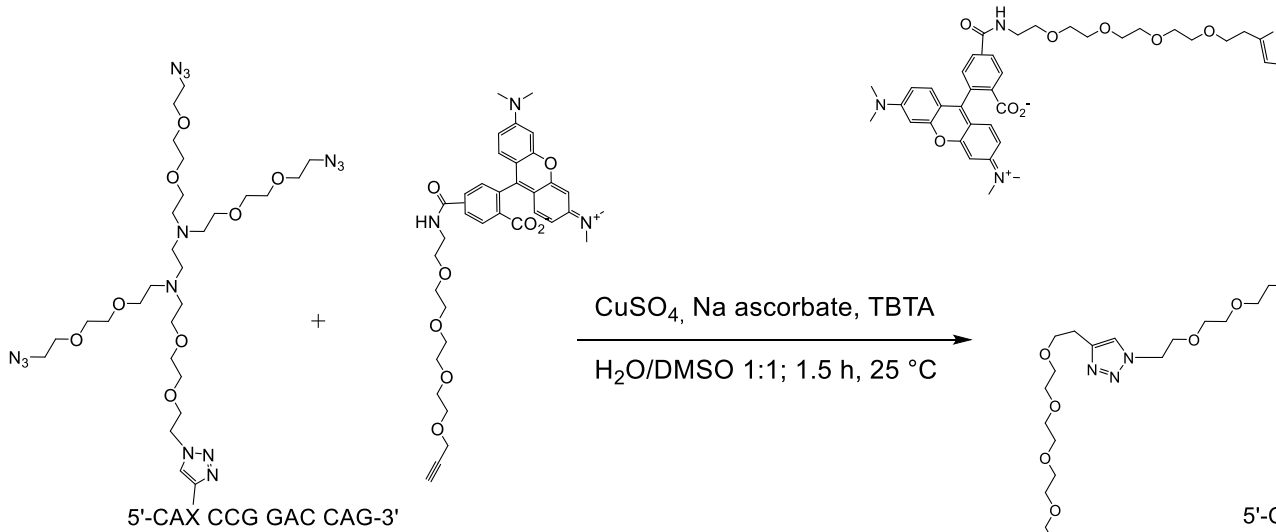

$\mathrm{CuSO}_{4}, \mathrm{Na}$ ascorbate, TBTA

$\mathrm{H}_{2} \mathrm{O} /$ DMSO $1: 1 ; 1.5 \mathrm{~h}, 25^{\circ} \mathrm{C}$

5'-CAX CCG GAC CAG-3'

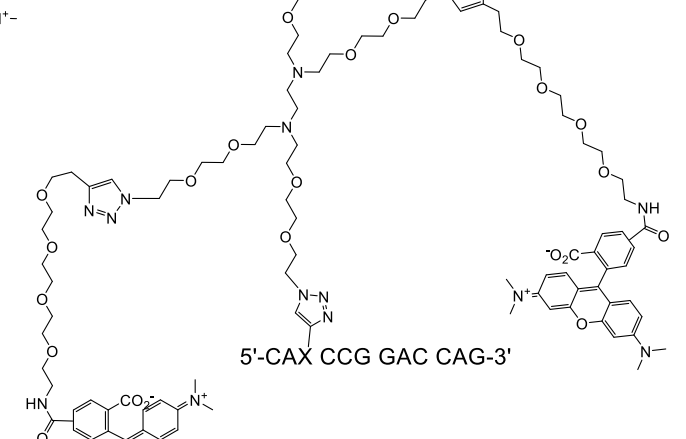

After the click reaction using the general procedure $\mathbf{A}$, analysis via RP-HPLC and MALDI-TOF-MS showed a quantitative conversion of the starting material to the clicked products. For the HPLC analysis and purification, the TAMRA maximum absorption wavelength $(546 \mathrm{~nm})$ was also monitored to identify the clicked products. The two intense peaks at 33.8 and $36.2 \mathrm{~min}$ can be assigned to the unreacted dye, while the product peaks have $t_{R}$ of 30.22 and 30.93 min (5/6-TAMRA isomers).

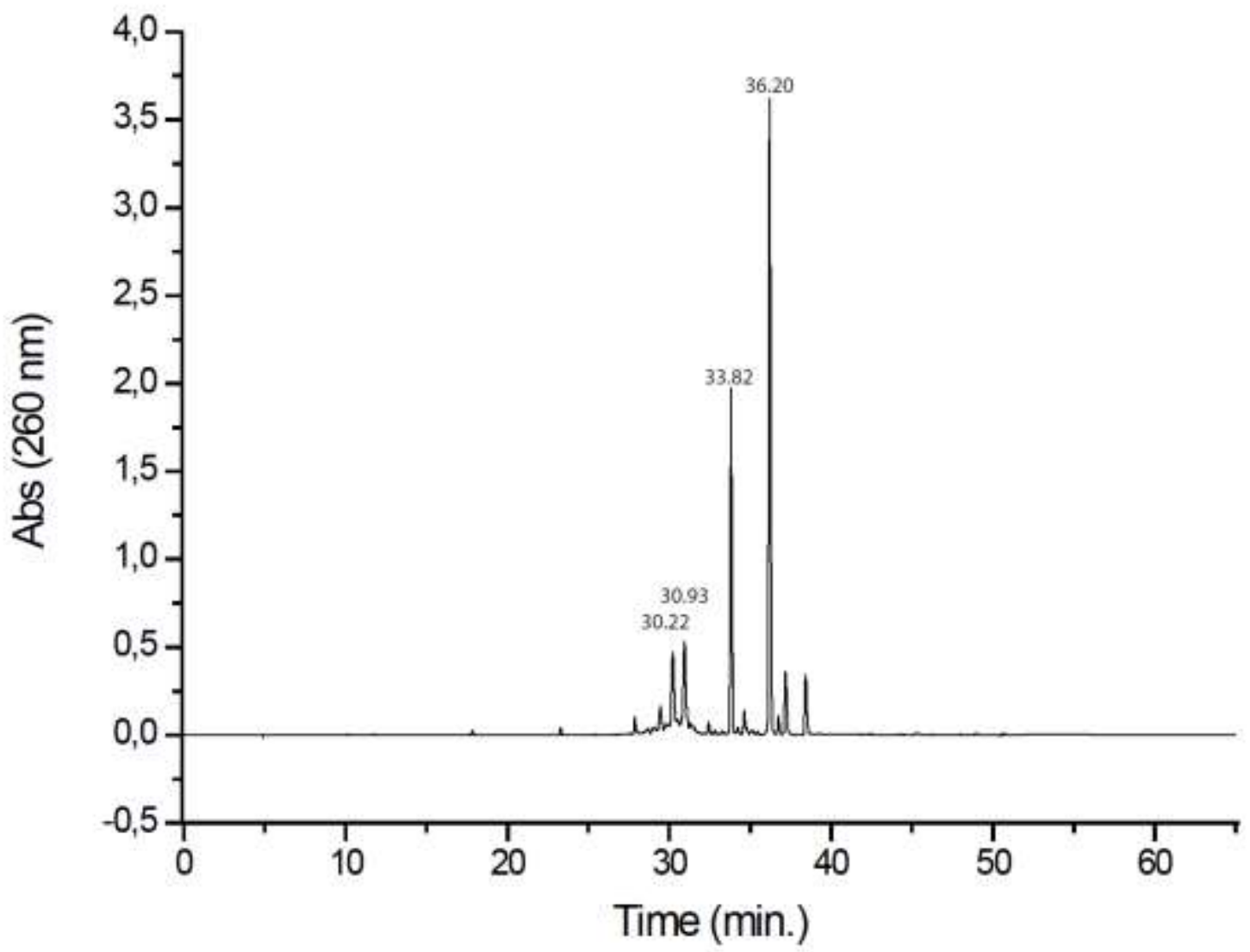


MALDI-TOF-MS: [M] calc. for oligonucleotide $1+$ dendrimer +3 dyes $=3705.4$; found $=6320.7,4687.1$ ([2 oligonucleotides $2+$ dendrimer +2 dyes $]^{2-}$ ).

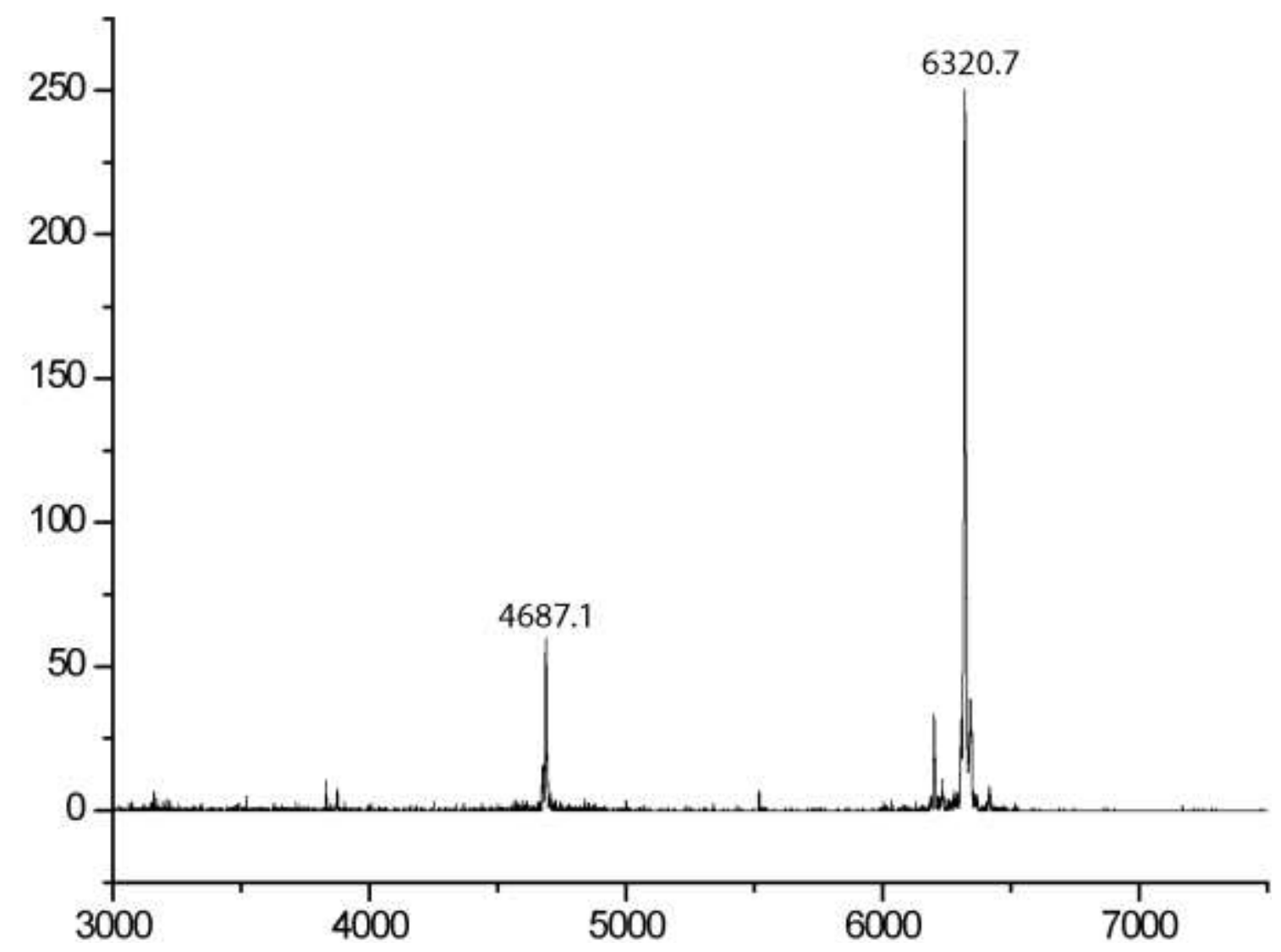

\section{Click reactions on solid phase}

After solid phase synthesis of the oligonucleotide 2 and DBU deprotection of the cyanoethyl groups of the phosphates, 2 click reactions were performed following the procedure $\mathbf{B}$ and the final product was analyzed by RP-HPLC and MALDI-TOF-MS. 

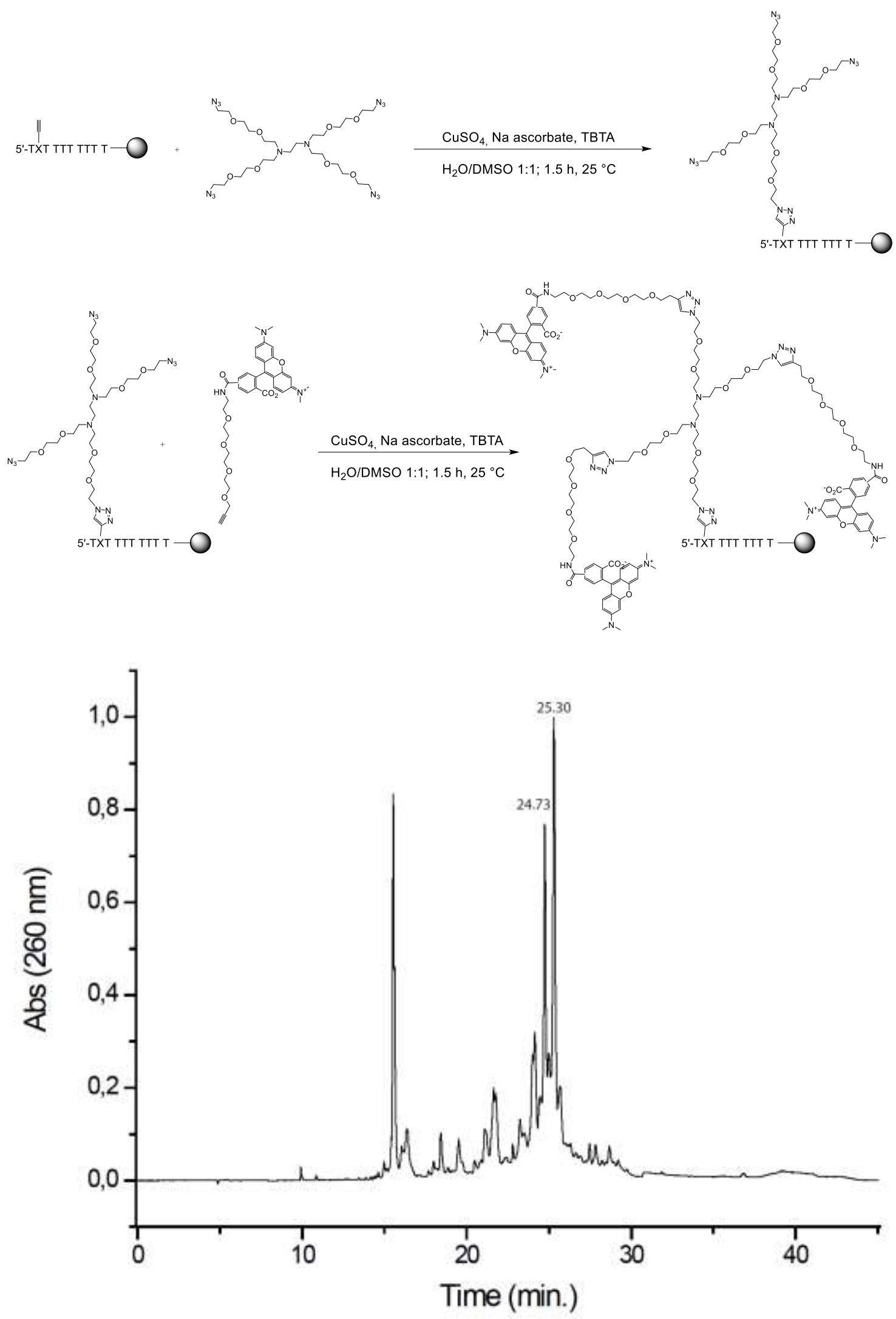

MALDI-TOF-MS: [M] calc. for oligonucleotide $2+$ dendrimer +3 dyes $=5612.4$; found $=5604.2$, $\left.3971.2(2 \text { oligonucleotides } 2+\text { dendrimer }+2 \text { dyes }]^{2-}\right)$. 


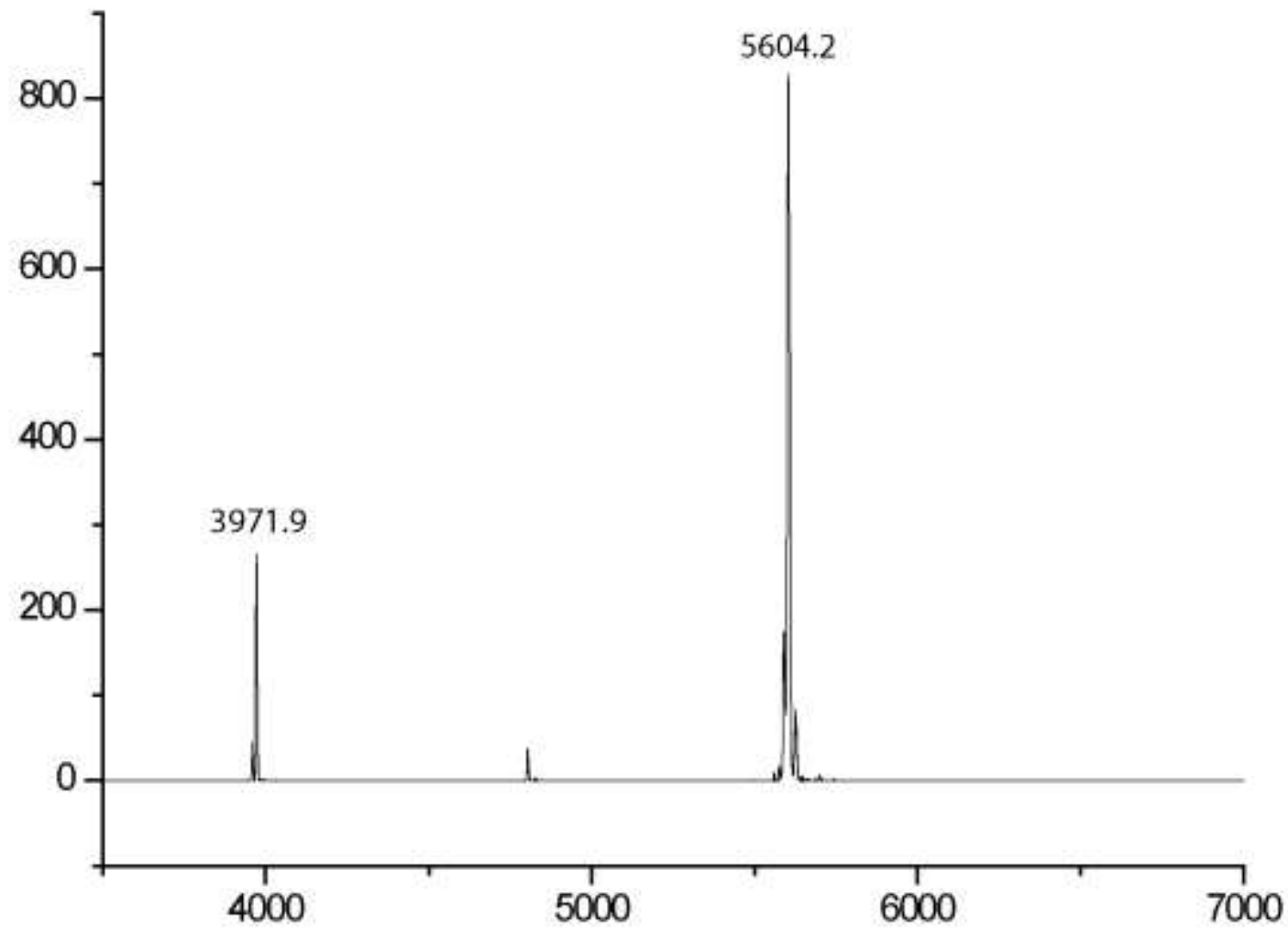

\section{Cell culture cell strains and EdU labelling in vivo}

HeLa, HEK293T and HEK293-GFP (GFP-stable cell line from Amsbio Catalog No. SC001) cells were cultivated at $37^{\circ} \mathrm{C}$ in water saturated, $\mathrm{CO}_{2}$-enriched $(5 \%)$ atmosphere. DMEM supplemented with 10\% fetal bovine serum (FBS) (Invitrogen \#10500-064), 1\% penicillin and streptomycin (Sigma Aldrich \# P0781), was used as growing medium. When reaching a confluence of $70 \%$ to $80 \%$, the cells were passaged in a new culture flask. For staining experiments, $1.5 \times 10^{4}$ cells were seeded in each well of a $\mu$-Slide 8 Well from ibidi (ibiTreat, \#1.5 polymer coverslip, catalog No. 80826) and cultured for two days or until a density of $80 \%$ is reached.

EdU dissolved in DMSO was added to the culture medium to a final concentration of $10 \mu \mathrm{M}$ for $1 \mathrm{~h}$ (HEK-GFP) and $2 \mathrm{~h}$ (HEK and HeLa). The control cells without EdU feeding were exposed to the same volume of DMSO biological grade for the same period. 


\section{EdU staining in situ for the control experiments}

All control experiments were accomplished using the EdU-Click kit from Baseclick $\mathrm{GmbH}$ containing the correspondent fluorescent dye and following the user manual.

\section{EdU staining in situ with the double click approach}

After EdU labelling, the cells were washed with phosphate buffered saline $(137 \mathrm{mM}$ $\mathrm{NaCl}, 10 \mathrm{mM} \mathrm{Na}_{2} \mathrm{HPO}_{4}, 1.8 \mathrm{mM} \mathrm{KH}_{2} \mathrm{PO}_{4}, 2.7 \mathrm{mM} \mathrm{KCl}$ ), supplemented with 0,02\% Tween (PBS-T) and fixed with 3,7\% Formaldehyde in PBS for 15 minutes at RT. All following steps could be done outside the sterile bench. After two washing steps with PBS-T, the first click cocktail containing $20 \mu \mathrm{M}$ tetraazide 1 was added to the cells. For this cocktail, the same buffers from the EdU-Click kit from Baseclick were used with the same final concentrations to prove, that any signal enhancement is caused by our dendrimer system. After $1 \mathrm{~h}$ incubation, the cells were washed twice with an acetic buffer $\mathrm{pH} 4.7$ for 10 minutes each followed by two short washing steps with PBS-T.

The second click cocktail containing the dye-alkyne to a final concentration of $5 \mu \mathrm{M}$ was then prepared and added to the cells and incubated for 30 minutes at RT. For the positive control, $20 \mu \mathrm{M}$ of dye-azide were used. Light was avoided to prevent bleaching of the dyes. After staining, the cells were washed twice with a saturated solution of guanidinium isocyanate for 10 minutes respectively followed by two washing steps with PBS-T. When preparing the click cocktails, all buffers have to be fresh. If precipitation or changes of the colors happen, use another bench of the buffers or solutions. Cells were then stained with $200 \mathrm{ng} / \mu \mathrm{L}$ DAPI for 10 minutes at RT and washed twice with PBS-T.

\section{EdU staining in situ with the triple click approach}

The same procedure, as described above, was used. After the first click reaction with $20 \mu \mathrm{M}$ tetraazide 1 and the washing steps with acetic buffer and PBS-T, the second click cocktail containing $5 \mu \mathrm{M}$ tetraalkyne 2 was added and incubated for $1 \mathrm{~h}$ at RT. After two washing steps with PBS-T, the click cocktail containing $20 \mu \mathrm{M}$ dye-azide was then prepared and added to the cells and incubated for 30 minutes at RT. After staining, the cells were washed twice with a saturated solution of guanidinium isocyanate for each 10 minutes followed by two washing steps with PBS-T. Cells 
were then stained with $200 \mathrm{ng} / \mu \mathrm{l}$ DAPI for 10 minutes at RT and washed twice with PBS-T.

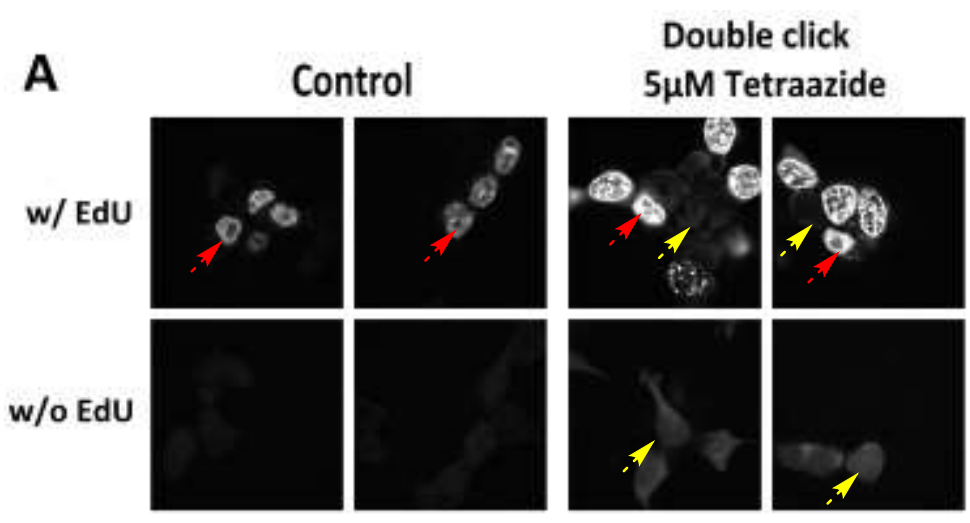

B

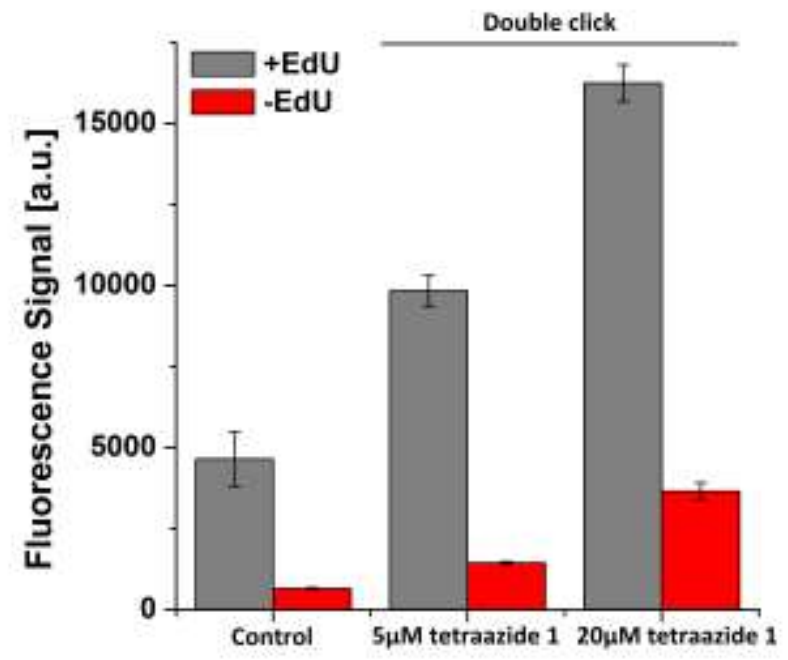

C

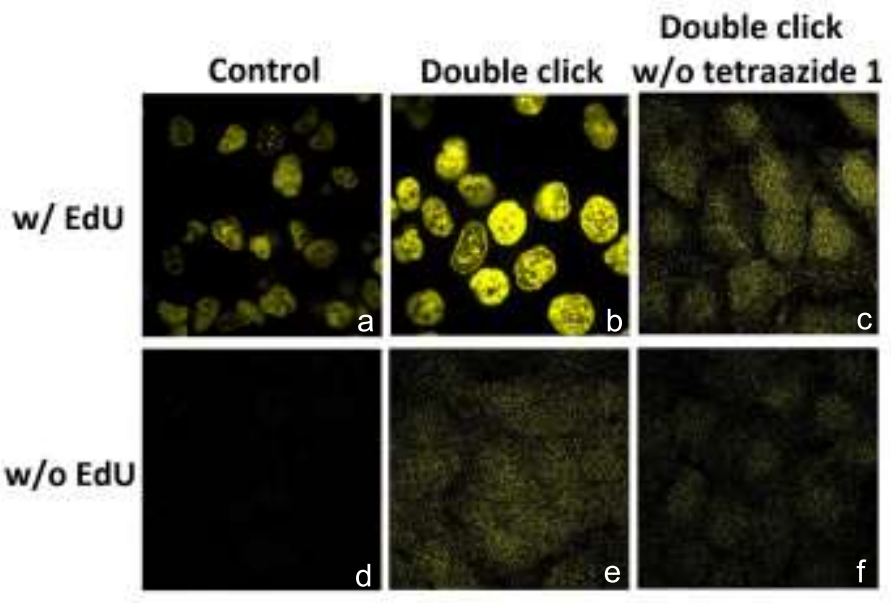

Supplementary figure S4: Development of the double click assay (simple dendrimer). A) A strong increase of the specific signal intensity (red arrows) was achieved with $5 \mu \mathrm{M}$ tetraazide 1 and $5 \mu \mathrm{M}$ Cyanine 3-alkyne. This enhancement was coupled with an increase of background fluorescence (yellow arrows), which was not seen in the control cells stained using the standard in situ click assay with $5 \mu \mathrm{M}$ dye 
azide. B) Using $20 \mu \mathrm{M}$ tetraazide $\mathbf{1}$, an enhancement of the signal intensity and the background were measured. C) To prove, that the signal intensity was generated by the combination of the tetraazide and the Cyanine 3-alkyne system, control experiments were done with EdU and Cyanine 3-alkyne (5 $\mu \mathrm{M})(\mathbf{c})$, without EdU, with tetraazide and Cyanine 3-alkyne $(5 \mu \mathrm{M})(\mathbf{e})$ and without EdU, without tetraazide and with Cyanine 3-alkyne $(5 \mu \mathrm{M})(\mathbf{f})$. Positive control was performed with EdU, tetraazide and Cyanine 3-alkyne $(5 \mu \mathrm{M})$. The negative controls $\mathbf{c}, \mathbf{e}$ and $\mathbf{f}$ show only background fluorescence without any kind of specific signal. Controls a and $\mathbf{d}$ were stained with $20 \mu \mathrm{M}$ Cyanine 3-azide. 
A
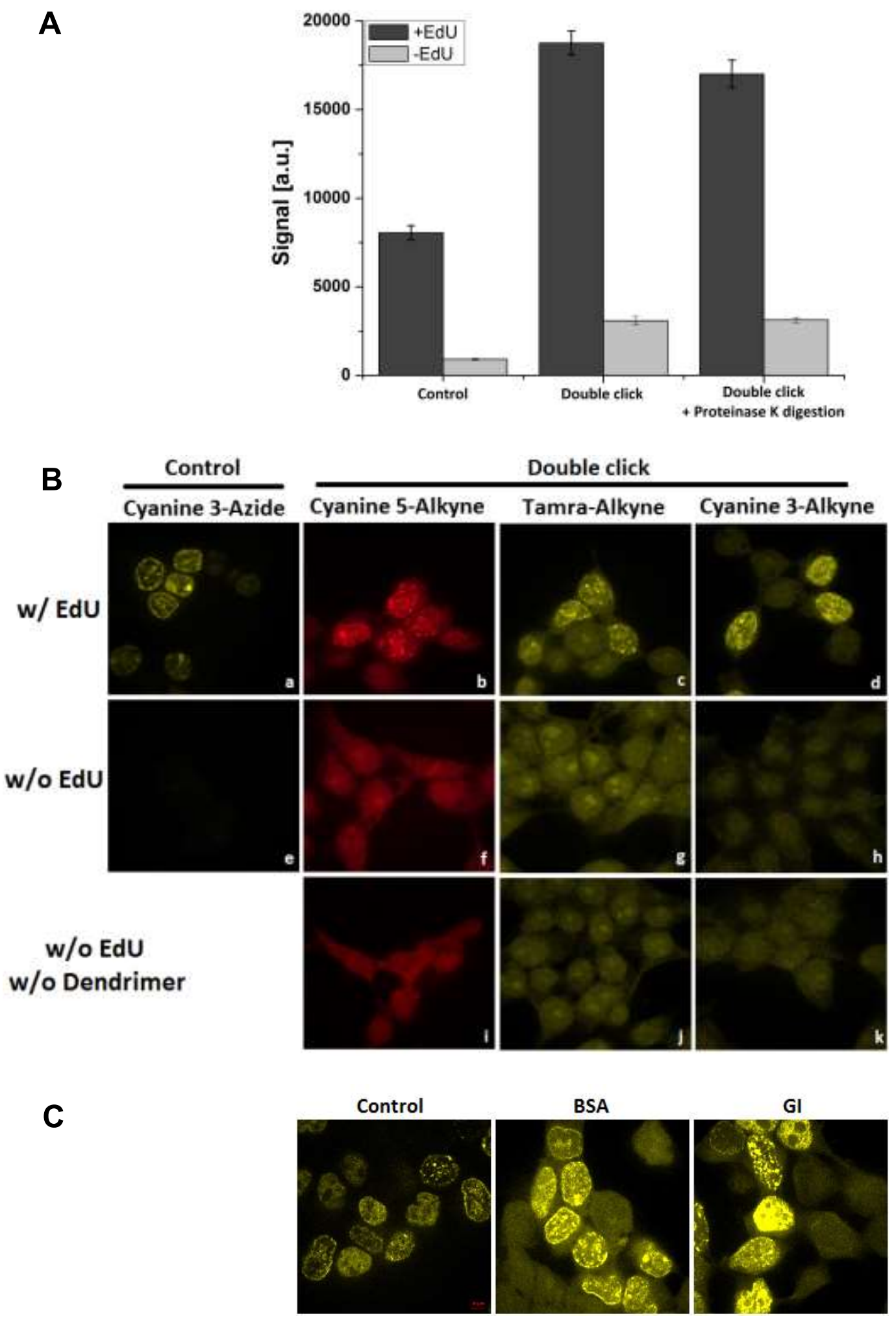

Supplementary figure S5: Improvement of the signal to background ratio of the double click assay. A) Digestion of proteins in order to reduce cross linkers, which could be binding sides for the alkyne-dye. Fixed and permeabilized cells were digested with $50 \mu \mathrm{g} / \mathrm{ml}$ Proteinase $\mathrm{K}$ at $37^{\circ} \mathrm{C}$ for $1 \mathrm{~h}$ before performing double click assay with dendrimer $1(20 \mu \mathrm{M})$ and Cyanine 3-alkyne $(5 \mu \mathrm{M})$. Control cells were stained using the double click assay without Proteinase $\mathrm{K}$ digestion and with $20 \mu \mathrm{M}$ 
Cyanine 3-azide. Positive control was the standard in situ click assay with cyanine 3azide $(20 \mu \mathrm{M})$. The specific signal intensity is after digestion slightly decreased. Negative controls without EdU labelling show no decrease in background signal intensity. B) Screening for dye alkyne. Positive control cells (a) labeled with EdU were stained with Cyanine 3-azide $(20 \mu \mathrm{M})$. For the double click assay, cells were labeled with EdU and stained using dendrimer $1(5 \mu \mathrm{M})$ followed by click reactions using either Cyanine 5-alkyne (b), Tamra-alkyne (c) or Cyanine 3-alkyne (d) (each 5 $\mu \mathrm{M})$. The double click assay was successful using the different dye-alkynes. For the negative controls, cells were not labeled with EdU but either stained with the dendrimer $1(20 \mu \mathrm{M})$ and the corresponding dye-alkyne $(5 \mu \mathrm{M})(\mathbf{e}-\mathbf{h})$ or only with the dye-alkyne $(5 \mu \mathrm{M})(\mathbf{i}-\mathbf{k})$. i-k were washed additionally over night with $3 \%$ BSA in PBS. They show how the dye-alkynes stuck strongly to the cells in an unspecific way. C) Screening for wash buffers. To decrease the unspecific bound dye-alkyne, a screening for organic (DMSO, DMF, Acetonitril, $\mathrm{MeOH}, \mathrm{EtOH}$ ) and inorganic washing solvents $\left(\mathrm{H}_{2} \mathrm{O}\right.$, Urea, guanidinium isocyanate, $\left.\mathrm{BSA}\right)$ was performed with different incubation times and temperatures (data not shown). The best washing buffer was guanidinium isocyanate (GI), which reduces the background signal of Tamra-alkyne by about $50 \%$ in comparison to $3 \%$ BSA in PBS, when used twice after the click reaction of the dye-alkyne and before DAPI staining for 10 minutes at RT. 


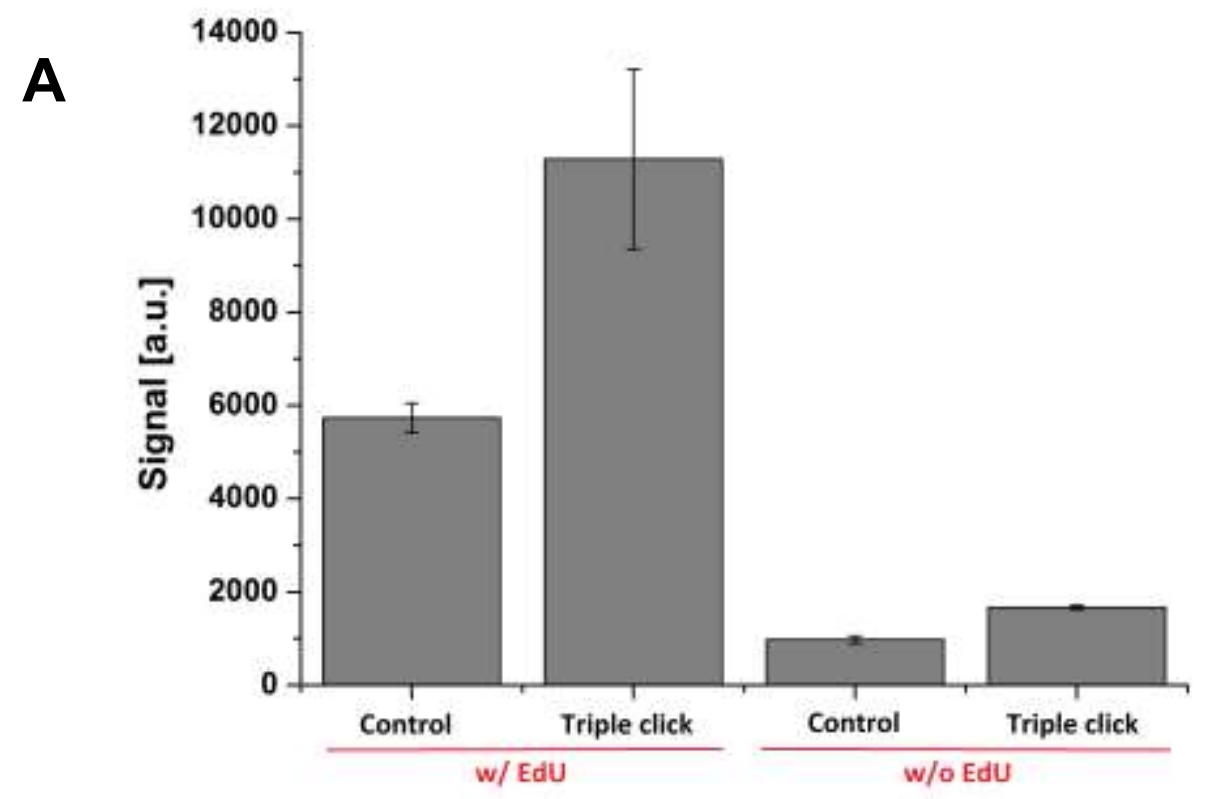

Triple click

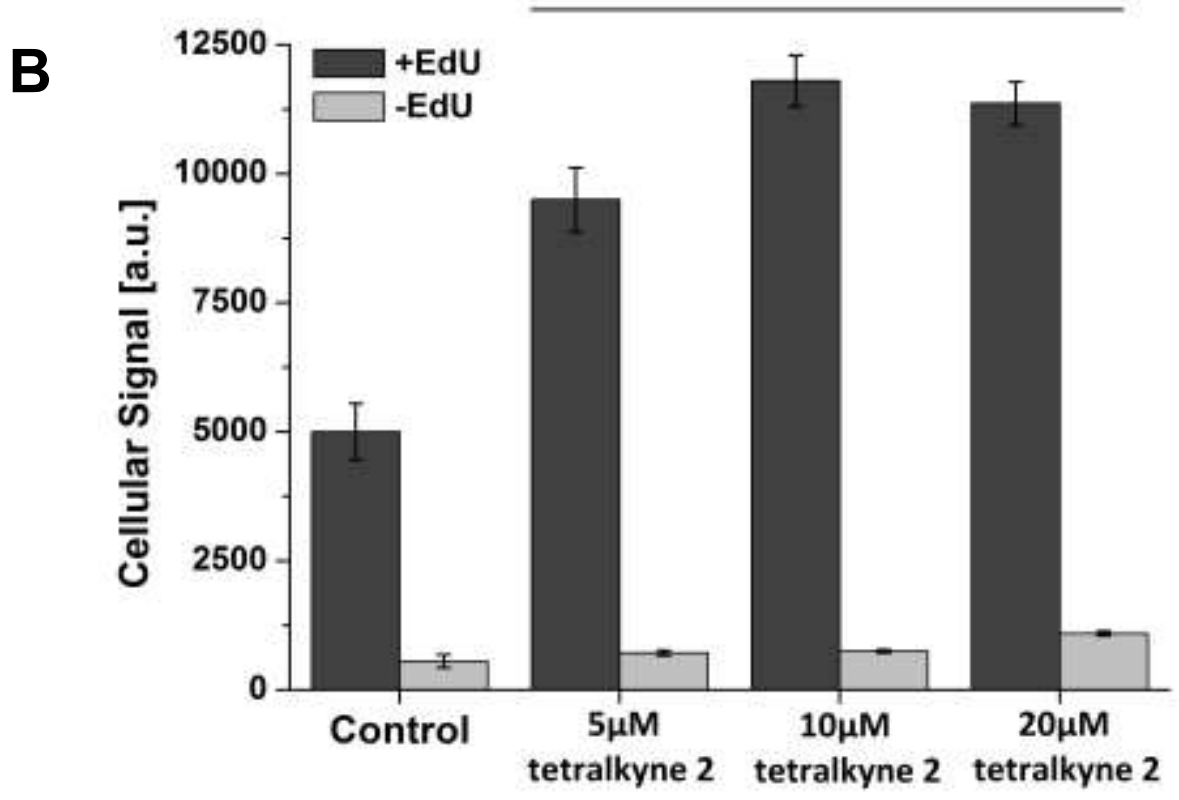




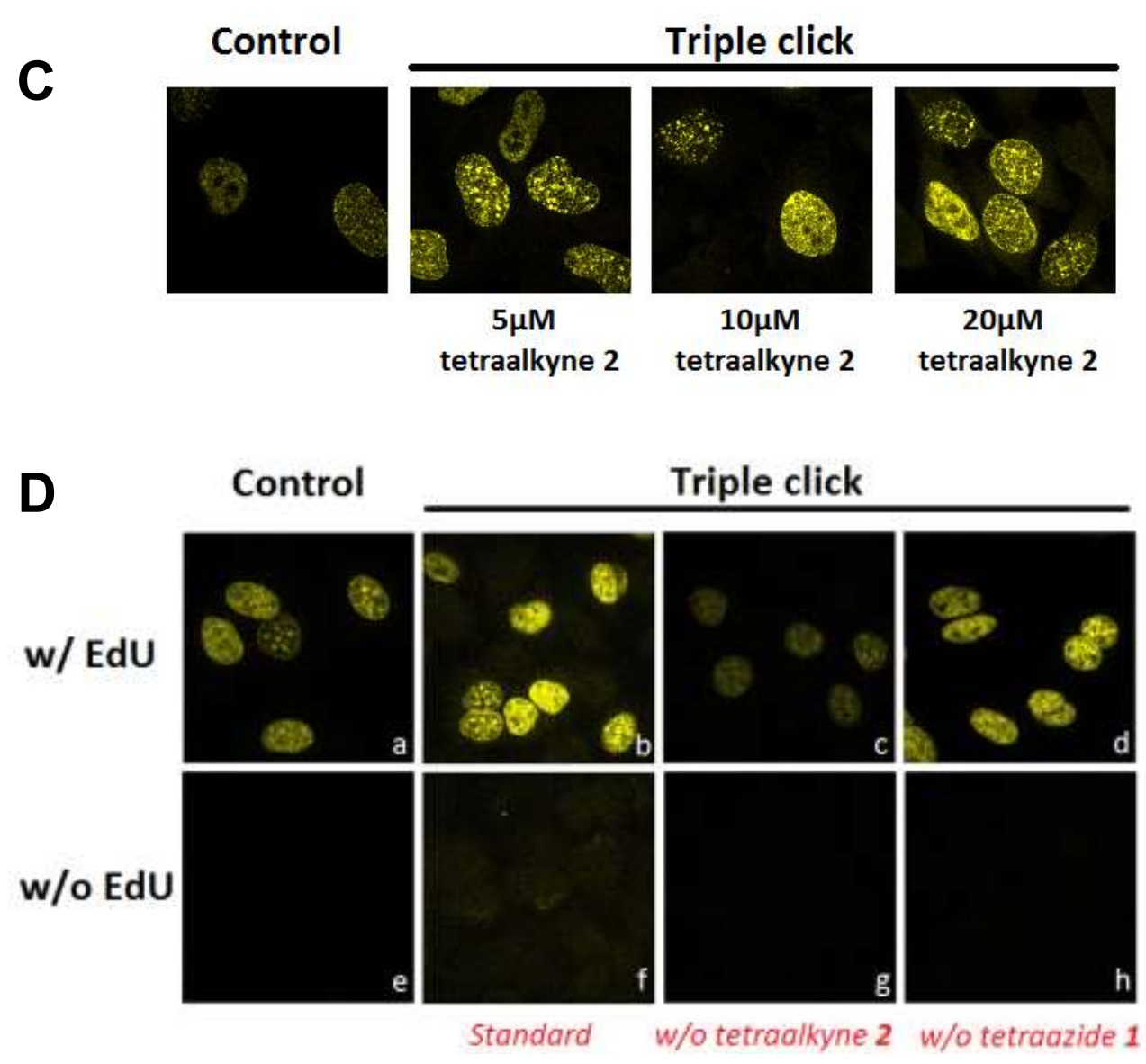

Supplementary figure S6: Development of the triple click assay (double dendrimer). A) An increase of the signal intensity and a reduced background signal were achieved using the double dendrimer approach. B) and C) Screening for the appropriate concentration of tetraalkyne 2 . A titration for the concentration was done using 5,10 and $20 \mu \mathrm{M}$ of the tetraalkyne 2 . The background intensity was dramatically reduced compared to the simple dendrimer assay. Furthermore, it was as low as the background in the control cells. The specific signal was doubled already with $5 \mu \mathrm{M}$ tetraalkyne 2. D) In order to test, if the increase of the specific signal intensity is a result of the combination of 1,2 and Tamra-azide, we performed control experiments either with $\mathbf{1}$ and without $\mathbf{2}(\mathbf{d}, \mathbf{g})$ or with $\mathbf{2}$ and without $\mathbf{1}(\mathbf{d}, \mathbf{h})$ respectively in presence or absence of EdU. Positive controls were the nondendrimer assay with (a) and without (e) EdU. c) shows that after the first click reaction, most of the genomic alkynes reacted with tetraazide 1 resulting in a very week specific signal. d) shows almost the same signal intensity as the positive control (a), because $\mathbf{1}$ cannot react with the genomic alkynes and is washed away before the click reaction with Tamra-azide. 

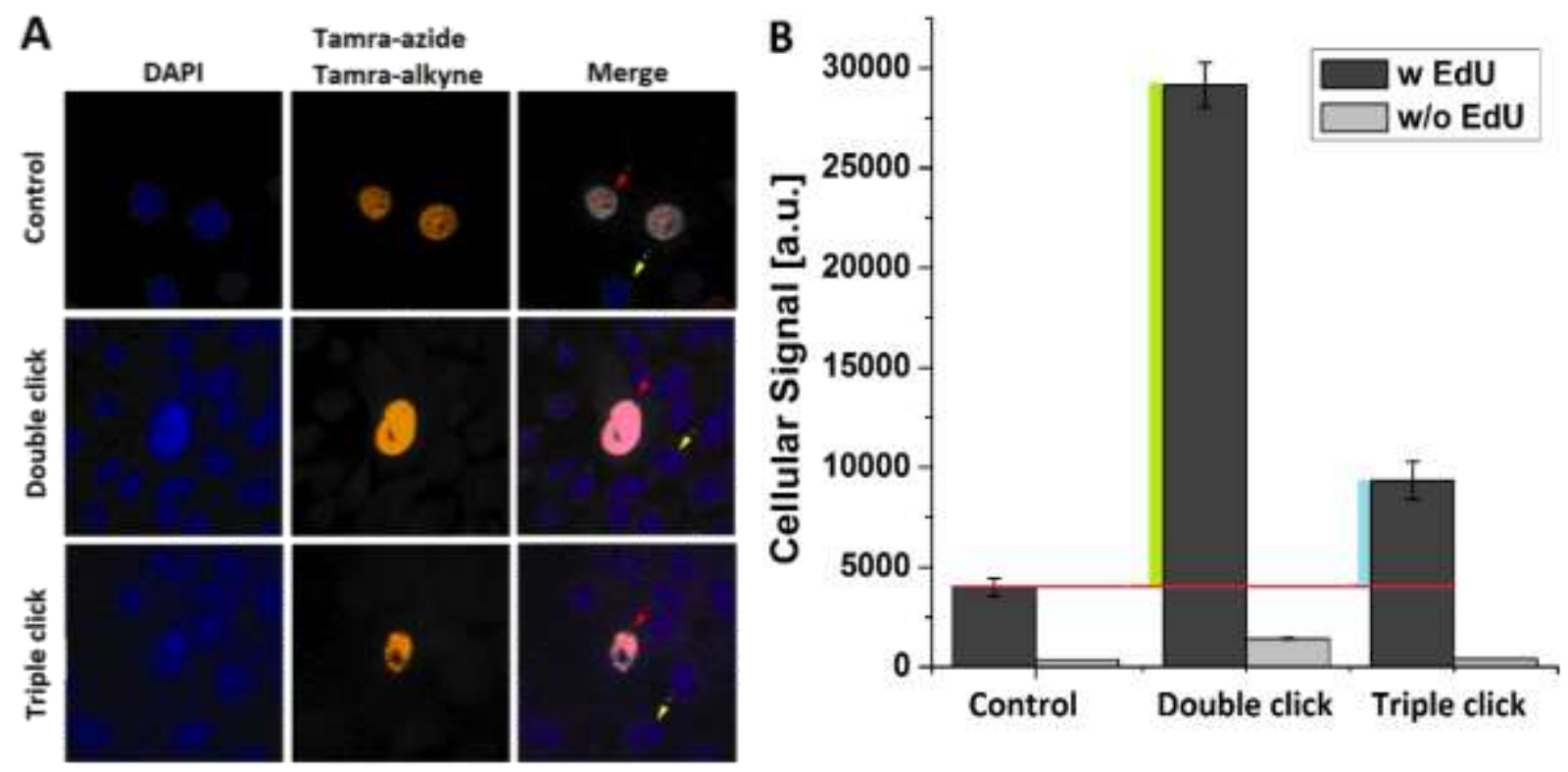

Supplementary figure S7: Direct comparison between the non-dendrimer, the double and triple click dendrimer approaches. A) Comparison of microscope images. The strongest signal of proliferating cells (red arrows) is achieved using the double click ( $20 \mu \mathrm{M}$ tetraazide 1 followed by $5 \mu \mathrm{M}$ Tamra-alkyne). The triple click (20 $\mu \mathrm{M}$ tetraazide 1 followed by $5 \mu \mathrm{M}$ tetraalkyne 2 and $20 \mu \mathrm{M}$ Tamra-azide) showed a doubling of the specific signal intensity. Yellow arrows show non-proliferating cells B) Statistical quantifications. These quantifications approve the signal enhancement seen under the fluorescent microscope. The signal intensity is at least doubled using the triple click and four times higher than the control using the double click approach. All other results obtained so far were confirmed. Due to the binding of several fluorescent dyes at the dendrimer 2 using the triple click, the cellular signal intensity is reduced compared to double click approach using only dendrimer $\mathbf{1}$. The reason for it could be the self-quenching of the fluorescent dyes.

High throughput screening: HeLa cells were seeded with different cell number $(100,500,1000,2000,4000,8000$ cells) in a 96-well black microplate with a flat bottom (VWR) for $48 \mathrm{~h}$. For each cell density, a duplicate was performed. Cells were fed with $10 \mu \mathrm{M}$ EdU for $2 \mathrm{~h}$. After fixation with 3.7\% PFA in PBS at RT and permeablization with $0.5 \%$ Triton in PBS-T for $15 \mathrm{~min}$ at RT, cells were incubated with $20 \mu \mathrm{M}$ tetraazide 1 followed by incubation with $5 \mu \mathrm{M}$ Tamra-alkyne for the double click assay. Cells were incubated with $20 \mu \mathrm{M}$ tetraazide 1 followed by $5 \mu \mathrm{M}$ 
tetraalkyne 2 than $20 \mu \mathrm{M}$ Tamra-azide for the triple click assay. All incubations were done in presence of $\mathrm{Cu}(\mathrm{I})$. The control cells were reacted only with $20 \mu \mathrm{M}$ Tamraazide in presence of $\mathrm{Cu}(\mathrm{l})$. Negative control cells without EdU labeling were reacted with the same corresponding reagents. The cellular intensities were measured with a microplate reader from Tecan for the positive and negative controls. Background intensity was measured and subtracted in order to calculate the specific signal intensity.

Microscopy and image analysis: Confocal fluorescence images were acquired by the commercially available Zeiss Cell Observer SD equipped with a Yokogawa spinning disk unit. Single slices of multiple nuclei within one field of view were acquired. The laser power and exposure settings were equal for throughout the image acquisition. Using ImageJ, a rolling ball background subtraction was performed, followed by determination of the gray value of the brightest pixel (GVBP). Then, a threshold at $0.25 \times$ GVBP was applied and the mean signal of the pixels above this threshold was measured. The mean of ten fields of view was taken and defined as signal for the respective condition. 